\title{
EL SEÑORÍO DEL OBISPADO DE BURGOS EN CANTABRIA EN LA EDAD MEDIA*
}

\author{
POR \\ CARMEN DÍEz HERRERA ${ }^{1}$ \\ Universidad de Cantabria
}

\begin{abstract}
RESUMEN
En este trabajo se analizan las características del señorío episcopal que los obispos de Burgos ejercieron durante la Edad Media en tierras de la actual Cantabria. Su patrimonio señorial en esa región, constituido tanto por los «monasterios propios» recibidos en la fundación dotacional y en donaciones de los monarcas castellanos del siglo XII, como por los privilegios y exenciones diversas de los que se beneficiaron, les permitió desempeñar un papel en la organización del territorio como señores feudales y sentar las bases de la estructura de la diócesis en dicho espacio.
\end{abstract}

PALABRAS CLAVE: obispado de Burgos; Cantabria; puertos del Cantábrico; señorío episcopal; «monasterios propios»; arciprestazgos.

\section{DOMINIONS OF THE BISHOPRIC OF BURGOS IN CANTABRIA IN THE MIDDLE AGES}

\begin{abstract}
This paper analyses the characteristics of the episcopal dominion the bishops of Burgos exercised in the territory of the modern Cantabria in the Middle Ages. Their estates in the region, consisting of proprietary monasteries received in the foundation endowment and as donations from twelfth-century Castilian monarchs, as well as several privileges and exemptions of which they benefited, allowed them to play a part in the organization of the territory as feudal lords and establish the basic diocesan structure in this area.
\end{abstract}

KEY WORDS: Bishopric of Burgos; Cantabria; Bay of Biscay ports; Episcopal lordship; Proprietary monasteries; Archpriests.

COMO CITAR ESTE ARTículo / CitATION: Díez Herrera, C. 2017. «El señorío del obispado de Burgos en Cantabria en la Edad Media». Hispania Sacra 69, 140: 439-454. doi: 10.3989/hs.2017.027

\author{
Recibido/Received 10-07-2015 \\ Aceptado/Accepted 31-07-2015
}

\section{INTRODUCCIÓN}

Desde 1068-1081², la mayoría del espacio que hoy constituye la comunidad autónoma de Cantabria quedó adscrita

* El presente artículo se inscribe dentro de las tareas del Proyecto: Cultura, poder y redes sociales en la Castilla Medieval: el clero diocesano y catedralicio de Burgos en la Baja Edad Media. HAR2013-41179-P.

1 carmen.diez@unican.es / ORCID iD: http://orcid.org/0000-00028496-1938

2 En 1068 se restaura la sede episcopal de Oca y en 1075 se crea la de Burgos como continuadora de la anterior. El proceso de asentamiento de la sede en Burgos culminará el 25-XII-1081, cuando Alfonso VI ofrezca a Jimeno II el palacio que había sido de Fernando I y la iglesia contigua de Santa María, para que en ella se estableciera la sede episcopal con su cabildo catedral. Garrido Garrido 1983a: n. 37 . Véase al respecto Martínez Díez 1984: 491-494 y 510. a la recién configurada Diócesis de Burgos. ${ }^{3}$ A partir de ese momento se iniciaría un prolongado y arduo camino con objeto de definir y defender los límites de la geografía episcopal y, sobre todo, para reivindicar, restablecer o desarrollar las variadas competencias propias del ejercicio de la actividad episcopal, el episcopale officium en el ámbito de la diócesis.

Nuestro interés en este artículo no ha sido conocer las distintas vicisitudes por las que hubo de pasar el obispado para llegar a ejercer todas las competencias inherentes a su autoridad en los términos de su diócesis. ${ }^{4} \mathrm{Ni}$ tampoco

\footnotetext{
3 Para observar este proceso puede consultarse Peña Bocos y Álvarez Llopis 2000.

4 La consagración de iglesias, la ordenación de sacerdotes y el nombramiento de los mismos para cada parroquia... Fortún Pérez de Ciriza 2013: 45-51.
} 
averiguar los diferentes conflictos a los que hubo de enfrentarse la sede burgalesa para conseguir que fueran reconocidos todos sus derechos por las instituciones que competían abiertamente por el poder en ese espacio desde otras sedes episcopales, caso de la de Oviedo, hasta los poderosos dominios monásticos con los que el obispado mantuvo frecuentes enfrentamientos, como ocurrió durante toda la Edad Media, con San Salvador de Oña. ${ }^{5}$

El objetivo concreto de este trabajo ha sido analizar las características del señorío episcopal que llegó a ejercer el obispo de Burgos, con independencia de su dominio eclesiástico, durante la Edad Media en tierras de la actual Cantabria. El obispo de Burgos, además de sus competencias como autoridad religiosa responsable en su diócesis, fue titular de unos señoríos, fue señor de tierras y hombres, en el ámbito o fuera de su obispado. ${ }^{6}$ Se observarán en primer lugar los medios de obtención de los bienes y derechos que constituyeron la base de su patrimonio dominical, así como la evolución del señorío. Y en segundo, las características de los bienes, derechos o prerrogativas del dominio de la iglesia de Burgos durante la Edad Media. Todo ello con objeto de intentar entender e interpretar el papel que, al margen de su labor y competencias episcopales y pastorales, pudo desarrollar el obispado, el obispo como señor feudal, en el espacio mencionado.

Miguel Rodríguez Llopis e Isabel García Díaz ya afirmaban en 1994 que los estudios sobre cabildos catedralicios contaban con una larga tradición historiográfica que se remontaba a la década de los 60 . Ambos autores, en su obra sobre Iglesia y sociedad feudal llamaron la atención sobre el desequilibrio en la distribución geográfica de los cabildos estudiados y sobretodo en la opción temática y temporal elegida por los historiadores. ${ }^{7}$ María José Lop Otín ofreció en el año 2003 una completa síntesis de los variados enfoques que han caracterizado la producción historiográfica sobre las sedes episcopales. ${ }^{8} \mathrm{~A}$ partir de ese momento han sido, fundamentalmente, los trabajos de Jorge Díaz Ibáñez con su análisis sobre El Obispado de Cuenca en la Edad Media $^{9}$, los de Francisco Javier Pérez Rodríguez y Manuel Antonio García Lamas en Galicia ${ }^{10}$, el de René Jesús Payo Hernanz, Jesús María Parrado del Olmo y el de Carmelo Luis López en Ávila. ${ }^{11}$ Los de Jesús Paniagua Pérez y Felipe Ramos (coord.) $)^{12}$ y Gregoria Cavero Domínguez ${ }^{13}$ en León y el de

\footnotetext{
5 Véase al respecto: Díez Herrera 2015; Pérez 2013.

6 En las fuentes se cita al abadengo que ejercía el señor obispo. Por ejemplo en el Becerro de las Behetrías: 467, al referirse al lugar de Torres se alude específicamente que era entonces abadengo del obispo de Burgos. La documentación episcopal denominaba vasallos a los habitantes de esos lugares. En el Libro de Apeos de la Dignidad Episcopal de 1515, figuran 670 vasallos. En el análisis de las rentas de la mesa episcopal se recoge las rentas señoriales que se percibían derivadas de ese concepto. Por ejemplo en las rentas de 1466 se registra que el obispo percibía la martiniega en varios lugares entre ellos en Pie de Concha. Casado Alonso 1980: 48 y 53.

7 Rodríguez Llopis y García Díaz 1994. Ambos autores ofrecen un estado de la cuestión sobre este tema.

8 Lop Otin 2003: 30-35. Esta autora sintetiza en su trabajo las diferentes formas con las que se habían abordado los estudios dedicados a los cabildos, especialmente en la Corona de Castilla.

9 Díaz lbáñez 2003.

10 Pérez Rodríguez 2010; García Lamas 2014.

11 Payo Hérnanz y Parrado del Olmo 2014; Luis López 2004.

12 Paniagua Pérez y Ramos (coord.) 2004.

13 Cavero Domínguez 2004.
}

Arturo Polanco Pérez ${ }^{14}$ en Palencia, los que han incrementado notablemente el conocimiento sobre distintos cabildos episcopales peninsulares. Más recientemente, Nicolás Ávila Seoane, ha realizado un estudio sobre el patrimonio señorial de la Catedral de Segovia. ${ }^{15}$

Respecto a la sede burgalesa, a pesar de su importancia en época medieval, no han sido abundantes los trabajos que el tema ha suscitado, a pesar de que desde 1983 están editados buena parte de los fondos de la Catedral. La nómina ha sido escasa: desde los imprescindibles trabajos de Serrano sobre El Obispado de Burgos, la contribución de Valdeón Baruque ${ }^{16}$, los trabajos de Casado Alonso sobre $L a$ propiedad eclesiástica en la ciudad de Burgos ${ }^{17}$, "La contribución de la diócesis de Burgos a la Hacienda Real en el siglo $X V{ }^{18}$, «Producción agraria, precios y coyuntura económica en la diócesis de Burgos y Palencia a fines de la Edad Media»" "¿¿Existió la crisis del siglo xIV? Consideraciones a partir de los datos de la contabilidad de la Catedral de Burgos $» .{ }^{20} \mathrm{O}$ la Memoria de Licenciatura de Pereda Llarena ${ }^{21}$, por citar los más específicos. Actualmente los trabajos sobre la sede burgalesa se han orientado más al análisis de la composición social, de las relaciones de poder y el clientelismo como demuestran los artículos de Susana Guijarro "Jerarquía y redes sociales en la Castilla medieval: la provisión de beneficios eclesiásticos en el cabildo de la Catedral de Burgos (1390-1440)»22, y el de Leticia Agúndez «Carreras eclesiásticas y redes clientelares en la Castilla bajomedieval: la provisión de beneficios menores en el cabildo de la catedral de Burgos (1456-1470)». ${ }^{23}$ O la tesis doctoral dirigida por la profesora Susana Guijarro recientemente defendida por Esperanza Simón Valencia sobre El cabildo de la Catedral de Burgos en el siglo XIV para ir ampliando notablemente el conocimiento del cabildo burgalés.

\section{LOS PROCEDIMIENTOS DE CONSTITUCIÓN DEL PATRIMONIO} DOMINICAL EPISCOPAL

Los medios de configuración del dominio patrimonial de los obispos de Burgos fueron los habituales y comunes en el desarrollo de cualquier tipo de señorío de época medieval, ya fuere éste de carácter monástico, episcopal, laico o solariego. En el caso burgalés fueron las donaciones de los monarcas castellanos, de sus familias, o de algunos miembros de la nobleza o de la aristocracia local las que contribuyeron en mayor medida a la constitución de su patrimonio ${ }^{24}$, siendo apenas testimonial lo adquirido mediante intercambios o permutas.

\footnotetext{
4 Polanco Pérez 2008.

15 Ávila Seoane 2008.

16 Valdeón Baruque 1970.

17 Casado Alonso 1980.

18 Casado Alonso 1982

19 Casado Alonso 1991.

20 Casado Alonso 2009.

21 Pereda Llarena 1986.

22 Guijarro González 2008.

23 Agúndez San Miguel 2014.

24 Buen ejemplo de esta dinámica de traspasos desde el realengo son las propias dotaciones fundacionales de los grandes monasterios o sedes episcopales. Martínez García 2007: 243-277.
} 


\section{Las donaciones}

En las donaciones debe destacarse el papel de algunos reyes castellanos como grandes benefactores del obispado burgalés. Sin duda, a ellos se debe la parte más sustancial y significativa en la configuración de su patrimonio señorial. Especialmente "generosos» se manifestaron la reina Urraca, y los monarcas Alfonso VII y Alfonso VIII. También recibieron donaciones de grandes magnates como Pedro Rodríguez, hijo del conde Rodrigo González de Lara ${ }^{25}$, así como de algún otro individuo de quien aunque sin título específico, el volumen y calidad de su patrimonio no deja lugar a duda respecto a su condición aristocrática. Estas donaciones no dejaron de ser muy poco frecuentes y nunca alcanzaron el valor de las cesiones reales.

Una categoría de donaciones efectuadas a los obispos de Burgos fue la constituida por la entrega de bienes. Algunos conllevaban derechos sobre hombres, es decir se trataba de bienes raíces con personas dependientes y otros, los menos, simplemente lo que se recibía eran inmuebles.

Otra categoría distinta de donación recibida fue la cesión de derechos, de privilegios a su favor. Este tipo de donación se inauguró con un privilegio atribuido al propio Sancho Il de Castilla en el que se concedía licencia a los obispos para que sus ganados pudieran pacer por varios montes de Cantabria, y autorización para poder pescar en piélagos, dehesas o puertos marinos entre los que se citan explícitamente el de Santa María del Puerto, el de San Emeterio, San Martín de la Arena y el de Afleca (La Rabia). ${ }^{26}$

Respecto al ritmo de donaciones, un primer lote provino de la propia dotación-restauración fundacional de la sede episcopal en el siglo XI y otro conjunto de donaciones fueron recibidas con posterioridad; las más significativas se llevaron a cabo en la duodécima centuria.

La posesión de diferentes bienes y derechos en territorio de Cantabria se inicia en la génesis de la propia sede episcopal burgalesa. Es decir, en la dotación fundacional. En efecto, de las redacciones que se han conservado sobre la restauración de la diócesis de Oca por decisión de Sancho II en 1068, se puede deducir que entonces fue cuando se incorporaron al patrimonio eclesiástico del obispado varios centros monásticos localizados en tierras de Cantabria que constituirán significativos pilares en el señorío de los obispos de Burgos y en la organización eclesiástica del obispado durante toda la Edad Media. ${ }^{27}$ En concreto, recibieron el monasterio de Santa María de Latas en Ribamontán al Mar con sus montes, fuentes y términos antiguos ${ }^{28}$, Santa María

25 En 1168 otorgó a la iglesia de Burgos sus propiedades en varios pueblos del alfoz de Cudeyo. Garrido Garrido 1983a: n. 174. Una zona que desde el siglo XI había sido conflictiva, disputada por los reinos de Castilla y Navarra, y que todavía en el s. XII era objeto de controversia.

26 Ibídem, n.으 22.

27 Ibídem, n.o 20 y 21. De hecho, alguno de ellos dará lugar a constitución de centros de arciprestazgos como Latas, Muslera, Cejancas o Pie de Concha.

28 Posiblemente situado donde ahora se encuentra el Santuario de Santa María de Latas en Loredo. Cofiño Fernández y Mazarrasa Mowinckel 2006: 126-127. La referencia a sus términos antiguos indica una ocupación anterior bien definida y delimitada. Sobre la trayectoria medieval de este monasterio puede consultarse Solórzano Telechea 2010: 254-256. de Muslera ${ }^{29}$, la cellulam de las ermitas de Campoo $^{30}$, el monasterio de San Facundo en Iguña y el de Santa Cruz en Valderredible. ${ }^{31}$ No obstante, hay que tener en cuenta que alguna de estas redacciones del documento se conserva a partir de copias del s. XIII, en las que puede ser muy posible que estos textos hubieran sido ya objeto de interpolaciones ${ }^{32}$, y que en realidad reflejen la composición del patrimonio dominical burgalés en esa última época. ${ }^{33}$

Otra etapa significativa en la recepción de donaciones al obispado comienza en el siglo XII. Se inaugura en 1101 con la entrega por D.a Godo, hija de García Armildez, de la cuarta parte del monasterio propio de Santa María de Tezanos en el valle de Carriedo. ${ }^{34}$ Y continúa poco después cuando el monasterio de San Facundo en Valdeiguña, en Silió$^{35}$, ubicado dominando la tradicional ruta de comunicación del Besaya, fue entregado, en el año 1120 por la propia reina D. a Urraca a la sede burgalesa, al obispo Jimeno y a los canónigos. Y como tal, aparece ya reconocido en el patrimonio eclesiástico en la bula del pontífice Lucio III, en el año $1182 .{ }^{36}$ Este monasterio, del que se conserva la espléndida iglesia románica actual, constituía en esa época un notable centro de realengo con varias decanías dependientes y obediencias (derechos sobre hombres). ${ }^{37}$

Ahora bien, hay que advertir que los responsables del mayor número de donaciones al obispado en ese periodo, como se detallará más adelante, fueron los monarcas Alfonso VII y especialmente Alfonso VIII. Por su iniciativa se transfirieron al obispado los monasterios de San Jorge de Toranzo, San Cristóbal de Bárcena de Ebro, San Miguel de Cejancas, Santa María de Fresno en Campoo, San Martín de Mazcuerras, además de la iglesia de Santa Leocadia en

29 Este centro monástico aparece en una segunda redacción. También con sus montes y heredades. Garrido Garrido 1983a: n.․ 21.

30 Con sus montes y sus pesquerías en el río Ebro. Ibídem: n. 20 y 21.

31 Ibídem: $n$. o 20 y 21

32 Esa es, al menos, la opinión de Martínez Díez 1984: 153.

33 De hecho, la siguiente información documentada fiable del monasterio de San Facundo de Iguña se refiere a cuando fue agregado a Burgos en 1120 por la reina D. a Urraca. Por ello es posible que, en efecto, alguna de estas versiones del privilegio de dotación de Sancho II recogiera la situación real del señorío del obispado a mediados del siglo XII.

34 Garrido Garrido 1983a: n.o 72. Ubicado, posiblemente, donde en la actualidad se encuentra la iglesia de Santa María de Tezanos, con algún resto románico.

35 Ibídem: $n$. 100. Del que se conserva la iglesia del mismo nombre, San Facundo, emplazada en la confluencia de dos caminos que enlazan dos barrios del pueblo. Uno de los caminos se denomina precisamente calle del monasterio por haber existido en ese lugar, según recuerda la tradición, el mencionado monasterio. Mesones Martínez 1965: 23.

36 Garrido Garrido 1983a: n.o 220. Tanto en esta bula como en la anterior de Alejandro III del año 1163, no aparecen todos los centros de culto que se hallaban adscritos a la iglesia burgalesa según consta documentalmente por otros textos conservados. Es posible que únicamente se buscara la sanción pontificia para aquellos centros que o bien por su situación geográfica o por su trascendencia económica resultaban muy interesantes para la sede burgalesa o bien porque su vinculación a la iglesia de Burgos estaba siendo cuestionada.

37 Según se puede deducir de la descripción de sus bienes anejos: "cum suis decaneiis, obedienciis et omnibus que ad prefatum monasterium pertinent, ubicumque sint». Garrido Garrido 1983a: n.ㅇ 100. 
Iguña. ${ }^{38}$ El obispado también recibió de Pedro Rodríguez, hijo del conde Rodrigo González participaciones en los monasterios de Bedía y Gajano, además de varias heredades en Cudeyo. ${ }^{39} \mathrm{Y}$ poco más tarde, en 1185 , el obispado continuó incrementando su patrimonio con las propiedades que recibe del conde Gonzalo Rodríguez en Ruerrero y Riopanero en Valderredible. ${ }^{40}$

\section{Los intercambios}

Los intercambios efectuados por el obispado fueron cuantitativamente insignificantes. Apenas se conocen más de cuatro permutas en la documentación burgalesa que afecten a territorio de Cantabria. Una de ellas fue la llevada a cabo por Alfonso VIII en 1185 mediante la cual se produjo la incorporación del monasterio de San Cosme y Damián de Cillaperriel al obispado a cambio del de Santa María de Villargura que el monarca destinó a la fabricación del monasterio de las Huelgas. ${ }^{41}$ Otra transacción muy significativa, también protagonizada por Alfonso VIII, fue la entrega del monasterio de Cervatos con iglesias, granjas y decanías dependientes así como con todos sus bienes y derechos $^{42}$ a cambio del monasterio de Santa Eufemia de Cozuelos. ${ }^{43}$ Este último monasterio fue cedido por el rey dos años más tarde a la Orden de Santiago seguramente para desde allí fortalecer y gestionar los bienes y derechos que la mencionada Orden tenía en la montaña palentina y sur de Cantabria. ${ }^{44}$

Unas características más confusas reviste el acto llevado a cabo por Diego González y su mujer D. a Elvira quienes entregan sus bienes, entre ellos unas vacas, que el obispo habría de recibir después de su muerte, a cambio de, entre otros motivos, poder elegir sepultura en la iglesia de Burgos. A su vez, el obispo le cede en prestimonio las tercias de varios lugares en concreto de Villasevil, Iruz, San Martín, Santiurde y Acereda, todos ellos, pueblos del valle de Toranzo. ${ }^{45} \mathrm{O}$ la entrega por la monja Fronilde de una divisa en una villa del mismo valle con el compromiso del obispado de proveerla, durante su vida, de varias prendas de vestido y calzado. ${ }^{46}$

38 Garrido Garrido 1983a y 1983b: n.o 110, 113, 164, 178, 239, 259. Con la adscripción de esos centros monasteriales a los obispos de Burgos se confirma de nuevo la afirmación de Martínez sobre que el abadengo, en este caso episcopal, se nutrió del realengo. Martínez García 2007: 252.

39 Garrido Garrido 1983a: n. 174.

40 Garrido Garrido 1983b: n. 254.

41 Ibídem: n. 259.

42 Ibídem: $n$. o 267. Le entrega cum omni iure et cum ómnibus directuris. Para entender la magnitud y extensión del dominio monástico de Cervatos puede consultarse el documento de la Catedral de Burgos del año 999. Garrido Garrido 1983a: n.o 10.

43 Monasterio en territorio de Herrera que el monarca Alfonso VI había concedido en 1075 al obispo de Burgos. En el año 1100 reitera la concesión al obispo de Burgos del monasterio con todos sus bienes, entre los que destaca el ornamento de la iglesia y la vajilla de plata y sobre todo, las decanías, villas pobladas y yermas, heredades... y una variada cabaña ganadera. Ibídem: n. 29 y 69.

44 Puede verse al respecto: Díez Herrera et alii. 2011: 80-81.

45 Garrido Garrido 1983b: n.o 349. Constituye un ejemplo de una forma de delegar en una familia local la gestión de las tercias episcopales.

46 Garrido Garrido 1983a: n. 63. En concreto, pellem et mantum et coopertum lineum vel laneum et sotulares.
Finalmente se registra otro cambio, el que llevó a cabo el obispo don Juan de todo el heredamiento que tenía en Pesquera y en sus términos: vasallos, tierras, viñas, casas... por un heredamiento en Moradillo de Sedano. ${ }^{47}$

Respecto a las adquisiciones parece que solamente se produjo una en el año 1243, en este caso de unos bienes que doña Sancha y su hermana, hijas del conde don Fernando, vendieron a don Juan obispo en varios lugares entre ellos en Valderredible por 300 maravedíes. ${ }^{48}$

\section{SOBRE LOS BIENES Y DERECHOS Y ÁREAS DE EXPANSIÓN SEÑORIAL}

La relación de bienes recibidos por todos estos medios proporciona las características del patrimonio señorial del Obispado de Burgos.

\section{Los monasterios y ecclesiae}

Por esta dinámica de traspasos del realengo al señorío episcopal, más de quince centros monásticos relevantes en territorio de Cantabria, pasaron entre los siglos XI al XII a ser gestionados por la iglesia de Burgos. La localización de esos enclaves religiosos y el análisis de sus bienes anejos pueden proporcionar algunas pautas para entender las características de su patrimonio y los posibles intereses que motivaron su incorporación al obispado burgalés.

Ya se ha hecho referencia a que en las distintas versiones de la restauración de la sede burgalesa con adiciones posteriores al año 1087, se recoge la concesión a Burgos de los monasterios de Latas $^{49}$ y el de Santa María de Muslera ${ }^{50}$, ambos con todas sus dependencias y vinculaciones feudales. ${ }^{51}$ Estas posesiones fueron ratificadas en la bula de Alejandro III en $1163 .^{52}$ En esa zona del litoral costero el obispado, desde 1168, también dispuso de una participación en el monasterio e iglesia de Bedía y en el de Gajano, al sur de la bahía de Santander, en el alfoz de Cudeyo. ${ }^{53}$ Con estas donaciones se configuró una de las áreas de expansión dominical del obispado de Burgos en Cantabria.

Otra área de expansión fue, sin duda, el valle de Toranzo donde el obispado recibió uno de los monasterios más significativos: el de San Jorge, cedido cum suis appendiciis al

47 Archivo Catedral de Burgos. V. 32, fol. 3. [En adelante mencionado A.C.B.].

48 A.C.B. V. 35, fol. 778.

49 Véase nota 28.

50 Santa María de Muslera, en Guarnizo, era la Santa María de Sovelias citada en el siglo IX en territorio de Camargo. El nombre de Muslera dio lugar a una circunscripción eclesiástica del obispado de Burgos: el Arciprestazgo de Muslera, conocido desde 1295. Véase Pereda Llarena 1984b: n.o 307. En el siglo XV Benedicto III a petición del obispo de Burgos Juan Cabeza de Vaca, confirmó la unión de esta iglesia de Santa María de Muslera al monasterio de Santa Marina de Don Ponce con todas sus rentas.

51 Garrido Garrido 1983a: n. 20.

52 Garrido Garrido 1983a: n. 165. Aparecen calificadas como ecclesiae, pero ya se sabe que se pueden denominar indistintamente iglesia o monasterio.

53 Ibídem: n.o 174. El de Bedia, posiblemente el monasterio de San Bartolomé, después iglesia parroquial de Elechas. El de Gajano puede ser el de San Martín, hoy iglesia parroquial del núcleo. Ambos convertidos ya en iglesias parroquiales aparecen en el Libro de Apeos de 151516. Huidobro y Serna 1934, 13/46: 302. 
obispo don Jimeno en 1128 por el monarca Alfonso VII. ${ }^{54}$ La entrega comportaba la cesión de un territorio bien delimitado, el término del monasterio, en el que se incluían tierras cultas e incultas, árboles, con y sin fruto, fuentes, prados, huertos, pesqueras, molinos, solares habitados y pendientes de poblar. Esta donación se confirmó y completó dos años más tarde con la concesión real de la exención de la justicia y de los tributos reales en el término, es decir con la confirmación de una nueva autoridad señorial fuera del alcance de los funcionarios regios, con lo que se consumó la transferencia del señorío. ${ }^{55}$ Posiblemente, la posesión de este monasterio facilitó al obispo la imposición y recaudación de los derechos episcopales de las iglesias parroquiales ya constituidas en el valle; el hecho de que en 1200 el obispo de Burgos otorgase en prestimonium las tercias (los tercios de los diezmos) de Villasevil, de Iruz, de San Martín, de San Jorge y de Acereda, muestra que el prelado ejercía ya, como máxima autoridad diocesana en el valle, alguna de sus competencias más significativas como la percepción de la tercia. ${ }^{56}$

Otro núcleo importante de poder del obispado, también merced a las donaciones reales fue el valle de Iguña. Allí, ya se ha comentado que desde al menos a comienzos del siglo XII el obispado y el cabildo dispusieron del monasterio de San Facundo en Silió por concesión de la reina Urraca, centro monástico al que, a su vez, estaban vinculadas diversas decanías y obediencias. ${ }^{57} \mathrm{Y}$ de hecho, según el Becerro de las Behetrías, en 1352 el obispo de Burgos mantenía en el lugar de Silió varios solares, algunos yermos, y sus vasallos tenían que abonarle periódicamente la fonsadera, la infurción y el nuncio, tributos, como es sabido, tradicionales de cualquier institución señorial. ${ }^{58}$ En 1128 fue el rey Alfonso VII el que incorporó al patrimonio burgalés la iglesia de Santa Leocadia en el mismo valle, iglesia del lugar de Helguera que ha conservado una necrópolis altomedieval, también con tierras, árboles, molinos, dehesas y pastos. ${ }^{59} \mathrm{Y}$ desde 1185, en esta ocasión por decisión del monarca Alfonso VIII, fue cedido mediante intercambio a la iglesia de Burgos y a su obispo don Marino, el monasterio de San Cosme y San Damián de Cillaperriel en Bárcena de Pie de Concha cum omni iure suo. Este enclave religioso que había desarrollado un señorío pertenecía a la familia real en concreto a la infanta Sancha, hermana de Alfonso VI, y controlaba un

\footnotetext{
54 Garrido Garrido 1983a: n.o 110.

55 Non sit ausus intrare ibi aliquis saio vel maiorinus sive regis vel alicuius alterius potestatis pro aliqua calumpnia sive pro furto vel homicidio vel fossadaria vel fornicio vel pro alia fiscali consuetudine. Ibídem: n. 0113 .

56 Garrido Garrido 1983b: n. 0349.

57 Garrido Garrido 1983a: n.o 100.

58 En 1424 el mayordomo del obispo arrendó a Diego López de Arenas los frutos de los préstamos de San Facundo de Silió. A.C.B. RR-5. Fol. 266-267. En Libro de Apeos del siglo XVI el obispado continuaba teniendo varios solares y heredades y percibía de San Facundo, probablemente ya solo iglesia parroquial, todo el diezmo, la ofrenda y las tres cuartas partes de las primicias. Huidobro y Serna 1934: n. 127:115 y n. $0128: 206$.

59 Garrido Garrido 1983a: n. 110. En Helguera se encuentra la iglesia de Santa Leocadia, actual iglesia parroquial, con trazas de arquitectura mozárabe del s. $x$, y restos de una necrópolis altomedieval de tumbas de lajas en su entorno. García Guinea y Pérez González 2007, II: 885. En el Libro de Apeos del siglo XVı aparece como una de las iglesias parroquiales del arciprestazgo de Cillaperriel.
}

conjunto de iglesias, parroquias y vasallos de realengo en una zona de especial relevancia en ese momento, finales del siglo XII, por el incremento del tráfico mercantil entre los puertos del cantábrico y la meseta castellana a través de la vía del Besaya. ${ }^{60}$ Esta permuta, por alguna razón cuestionada, hubo de ser ratificada por el propio Alfonso VIII dos años mas tarde. ${ }^{61}$ En esta zona el patrimonio burgalés se consolidó de manera que, según la pesquisa recogida en el Becerro de las Behetrías, el obispo y la iglesia de Burgos mantenían en el siglo xIV solares en Silió, en Pie de Concha y en varios barrios de Molledo. ${ }^{62}$ De hecho, Cillaperriel se convirtió en un arciprestazgo de la diócesis ${ }^{63}$ que, en el siglo XVI, tenía como centro la villa de Pie de Concha donde el señor obispo tenía unos palacios junto a la iglesia, disponía de la jurisdicción civil y criminal sobre sus vasallos, los vecinos de Pie de Concha, de Bárcena y de Cobejo...y percibía sus derechos episcopales en más de dieciocho iglesias. ${ }^{64}$

Otro centro de gran interés, por su proximidad al yacimiento salinero de Cabezón, que quedó bajo el control de los obispos de Burgos fue el monasterio de San Martín de Mazcuerras en el alfoz de Cabezón (Cabezón de la Sal). ${ }^{65}$ Este monasterio constituía, a finales del siglo xII el centro gestor de un señorío de realengo que incluía varias dependencias e iglesias vinculadas, posiblemente las del entorno de Mazcuerras; ¿algunas de sus ermitas de factura medieval? ${ }^{66}$, ¿̇la iglesia de Cos (con una tradición de ocupación desde el siglo VIII) ${ }^{67}$, o la de Ibio ${ }^{68}$, y un conjunto de vasallos. Estos bienes y derechos, por decisión de Alfonso VIII, pasaron a propiedad de don Marino, obispo de Burgos en el año $1184 .{ }^{69}$ Precisamente, en 1229 el rey Fernando III confirmó a los vasallos de ese monasterio, el de San Martín de Mazcuerras, que no tenían que pagar homicidium ni ningún pecho ni conducho a ricohombre a no ser al obispo. ${ }^{70}$ En el siglo XIV, según el Becerro de las Behetrías, el lugar de Mazcuerras aún pertenecía íntegramente al obispo y a su

60 Además de las heredades, solares, pastos, etc. Garrido Garrido 1983b: n. 259. La iglesia románica datada en el s. XII estaba situada en el antiguo camino real.

61 Ibídem: n.․ 272

62 Martínez Díez (ed.) 1981: 156, 179 y 124.

63 Conocido desde el siglo XII. Escagedo Salmón 1926: 268.

64 Huidobro y Serna 1934: n.o 127: 114-117.

65 Garrido Garrido 1983b: n.o 239. Posiblemente situado en el lugar donde posteriormente, en el siglo XVII, se levantó la iglesia actual de San Martín. Actualmente han aparecido unos fragmentos de epígrafes de factura altomedieval. Mazcuerras constituía un asentamiento privilegiado en el valle medio del Saja, al pie de la sierra del Navajo junto al rio Saja con abundantes recursos forestales.

66 Como la ermita gótica de Cintul, próxima al río Pulero, en la divisoria entre Mazcuerras y Cos. O la ermita de San Pedro o la de Santa Gadea en Mazcuerras.

67 Con una necrópolis de tumbas de lajas datada en torno al siglo VIII y con restos románicos del siglo XIII en su iglesia. Ruiz de la Riba et alii. 1994. Además en el siglo XVI el obispo recibía la mitad de los diezmos de Cos. Huidobro y Serna 1934: n. 46: 17.

68 En el siglo XVI el obispo percibía un tercio de la renta de esta iglesia. Garrido Garrido 1983a: n. 46: 17.

69 Garrido Garrido 1983b: n.o 239. El monarca cede el monasterio integro: cum ingressibus et eggresibus cum terminis et frontariis, et cum omnibus ecclesiis suis, cum collaciis et solaribus populatis et heremis, cum terris, ortis, pratis, pascuis et aquis, cum montibus et fontibus et arboris fructuosis et infructuosis et cum omnibus directuris et pertinenciis suis.

70 A.C. B. V.34. Fol. 346. 
iglesia. ${ }^{71}$ Y según la información que proporciona el Libro de Apeos del siglo XVI parece que entonces ya solo sobrevivía la iglesia y se afirmaba que el monasterio, del que únicamente quedaban sus cimientos fuera de la cerca del cementerio, había sido de los frailes templarios. En esa misma época el obispado de Burgos disponía de un pozo en Cabezón del que recibía de sus arrendatarios; "dos partes del tercio de dos celemines de sal por semana»..$^{72}$

La última área de expansión del señorío del obispado de Burgos estuvo situada en la zona meridional de Cantabria. ${ }^{73}$ En concreto en Campoo donde dispusieron del monasterio de Santa María de Fresno ${ }^{74}$ y del de San Pedro de Cervatos por concesión de Alfonso VIII. Este último monasterio fue incorporado al patrimonio episcopal en el año 1186 por decisión del monarca a cambio de la cesión de Santa Eufemia de Cozuelos. $^{75}$

Según el Becerro de las Behetrías se afirma que el lugar de Pesquera también en la comarca de Campoo, era abadengo del obispo de Burgos. ${ }^{76}$ En este enclave, (del que se conserva la lápida de consagración de su iglesia de San Miguel por el obispo de Burgos don Gómez del siglo XI), dispuso el obispado de diversos bienes y vasallos ${ }^{77}$ y fue, desde finales del siglo XIII, sede de uno de los arciprestazgos de la diócesis. ${ }^{78}$ En el Libro de Apeos del siglo XVI se afirma que el lugar de Pesquera era cámara del obispo y sus vecinos vasallos, lo mismo que los de los lugares de Serna, Concha y Porciles. El obispo disponía allí de la jurisdicción civil y criminal, alto, bajo y mero mixto imperio por ello existía en el

71 Este logar es del obispo de Burgos e de su iglesia. Pagaban derechos al rey y al señor obispo infurción cada solar, nuncio y mañerías. Martínez Díez (ed.) 1981: 191.

72 Huidobro y Serna 1934: n. o 46: 16 y 17.

73 Véase al respecto. Pereda Llarena 1984a: n.o 126.

74 Garrido Garrido 1983a: n.164. Monasterio actualmente desaparecido. García Guinea y Pérez González 2007, III: 1505. En 1182 Lucio III, en una bula, confirmaba esta posesión a la dignidad episcopal de Burgos. Ibídem: n. 220. En el siglo xIV parece que el obispado no mantenía en el lugar ningún vasallo. Martínez Díez (ed.) 1981: 526. En 1423 la renta del monasterio fue arrendada durante cuatro años a López de Hoyos, Caballerizo mayor del rey, pero algo debió suceder porque dos años más tarde el mismo mayordomo del obispo la cedía en arriendo a Juan Rodríguez de Villegas. A.C.B. RR-6. Fol. 175 y 232v-233. En El Libro de Apeos de la Dignidad Episcopal, escrito entre los años 1515 y 1516 , se afirma que la sede tenía allí prados y tierras que pertenecían a Santa María de Fresno, que había sido monasterio propiedad del obispo y que el mismo arrendaba los diezmos de la iglesia, por lo que se puede deducir que únicamente sobrevivía la iglesia, ya parroquial. Huidobro y Serna 1934: n. 127: 112-113.

75 Garrido Garrido 1983b: n.o 267. Se sabe que en la abadía de San Pedro de Cervatos existía un cabildo presidido por un abad que también era dignidad del cabildo burgalés estableciéndose una articulación entre la colegiata y la iglesia catedral. Como afirma Hilario Casado, la abadía de Cervatos aparece dentro de la comunidad capitular desde la «Concordia Mauriciana» de 1230. Casado Alonso 1980: 32. En el Libro de Apeos, los testigos llamados a declarar sobre los derechos episcopales en Cervatos afirmaron que cuando el obispo visitaba en persona el monasterio, el abad le proporcionaba un yantar a él y a su compañía. Huidobro y Serna 1934: n. 127: 112.

76 Salvo dos solares realengos, el de Porciles, despoblado en Rioseco y en Lanchares, donde el obispado compartía señorío con otros de behetría y solariego. Martínez Díez (ed.) 1981: 467, 468, 469.

77 El obispo Don Marino recibió en 1193 unas domos en Porquera. Garrido Garrido 1983b: n. o 311. En 1424 el obispado disponía allí de un monasterio. A.C.B. RR-5. Fol 266-267.

78 Ello se deduce de la información conservada en el documento de Pérez Llarena 1984a: n.o 126. En esa época era Arcipreste Pero Abad. lugar horca, picota, cepo y cadena. ${ }^{79}$ Tenía una torre de cal y canto y percibía la infurción de 29 solares, además del tercio de lo que se diezmaba en las iglesias de Porciles, Rioseco, Santurde, Lantueno, Sonvalle y Aguayo. ${ }^{80}$

En Valderredible, donde desde la propia dotación inicial de la sede burgalesa el obispado burgalés poseía el monasterio de Santa Cruz ${ }^{81}$ y donde, por concesión del monarca Alfonso VII, al menos desde el año 1128, el obispado dispuso también del monasterio de San Cristóbal de Bárcena de Ebro. ${ }^{82}$ También los prelados contaron con heredades en Ruerreros y en Riopanero en el mismo valle por concesión del conde Gonzalo. ${ }^{83}$ En el siglo XVI se constata la existencia del arciprestazgo de Santa Cruz del Valle que, aunque en ese momento el lugar estaba despoblado, era cabeza del arciprestazgo y pertenecía al señor obispo que había mandado construir allí, recientemente, una nueva iglesia. ${ }^{84}$ No debieron ser las únicas posesiones que el obispado tuvo en ese territorio pues por la bula emitida por Lucio III en 1182 se sabe que la sede burgalesa estaba en posesión de las Behetrías del monasterio de San Esteban de Villota de Helines..$^{85} \mathrm{Y}$ el Becerro trasmite que el obispo de Burgos tenía vasallos en 1352 en Villamoñico, también en Valderredible. ${ }^{86}$

En el alfoz de Bricia, la sede burgalesa dispuso del monasterio de San Miguel de Cejancas ${ }^{87}$ junto con otro monasterio vinculado, el de San Julián ${ }^{88}$ con todas sus propiedades y derechos. ${ }^{89}$ En este caso también fue el monarca Alfonso VIII el dadivoso donante. Este lugar, Cejancas, continuaba en el siglo XIV como abadengo del obispo de Burgos ${ }^{90}$ y en el siglo XVI constituía un arzobispado en el que el prelado burgalés percibía el tercio de lo que se diezmaba en más de sus 36 iglesias parroquiales. ${ }^{91}$

79 El municipio conserva aún una interesante picota o rollo.

80 Huidobro y Serna 1934: n.o 127: 113.

81 Garrido Garrido 1983a: n. 19. Debía de estar situado muy próximo a Berzosilla y a Villamoñico. La posesión de esta eclesia o monasterio perteneciente a la dignidad episcopal es confirmada en 1163 por la bula de Alejandro III. Ibídem: n. 165 .

82 Garrido Garrido 1983a: n. 110. Denominado también Bárcena de Reocín, en el siglo XVI constituía un arzobispado donde el obispo percibía los diezmos del monasterio de San Cristóbal y el tercio en otros varios lugares. Huidobro y Serna 1934: n.o 127: 111.

83 Garrido Garrido 1983b: n. 254.

84 El arciprestazgo incluía Santa Cruz del Valle, Berzosilla, Villanueva de Alfanía y Villamoñico. La nueva iglesia se había construido en términos del monasterio, cerca de unos casares caídos «donde era el pueblo». Huidobro y Serna 1934: n. 127: 110.

85 Garrido Garrido 1983a: n.ㅇ 220. Del lugar de Villota se dice en 1352 que estaba yermo y que era solariego de la iglesia de San Martín de Helines. Martínez Díez (ed.) 1981: 517.

86 Martínez Díez (ed.) 1981: 498. De hecho en el siglo XVI el obispado conservaba en Villamoñico un pradillo y dos solares a renta. Huidobro y Serna 1934: n.o 127: 110.

87 En torno a la iglesia parroquial, construcción del siglo XIII, se encontró un sarcófago medieval.

88 Este monasterio puede ser el de Bricia o el de Montejo, ambos bajo la advocación de San Julián, del arciprestazgo de Cejancas en el s. XIV. Huidobro y Serna 1934: n.o 129: 306.

89 Garrido Garrido 1983a: n.o 178. En la donación se incluían molinos, pesqueras, casas, derechos de pastos y collazos. En 1352 Cejancas de Suso, (despoblado en el término de Cejancas,) era considerado lugar de abadengo del obispo de Burgos y el obispo percibía la cuarta parte de la martiniega, es decir 15 maravedíes. Martínez Díez (ed.) 1981: 484.

90 Martínez Díez (ed.) 1981: 484.

91 Huidobro y Serna 1934: n.129: 306-307. 
Resulta muy difícil diferenciar el concepto de ecclesiae respecto de las menciones a monasterios porque el hecho de que los monasterios dispusieran de iglesia, donde en muchas ocasiones, los propios monjes o presbíteros o clérigos nombrados por ellos, prestaban atención pastoral a los fieles del lugar, provocaba que se les denominara indistintamente de una forma u otra. ${ }^{92}$ Por ejemplo en el año 1106 se menciona con la categoría específica de iglesia, la de Santa María de Ruerreros, en Valderredible, fundada por D. a Sancha, familiar de los donantes que entregan la parte que les corresponde al obispo García. ${ }^{93} Y$ sin embargo a través de otro texto conservado se conoce que era un "monasterio propio» que había heredado de sus parientes y que a su vez disponía de decanías, divisas y collazos además de tierras y viñedos. ${ }^{94}$ Aparece con la categoría de ecclesia la de Santa Leocadia de Iguña, de propiedad real, cedida a Burgos en $1128^{95}$, así como las de Santa María de Valdeprado y Santa Cruz de Valderredible, según recoge la bula de Alejandro III de $1163 .{ }^{96}$ En la misma situación se encontraba las de San Pedro de Castrillo y la de Santa María, ambas en Castrillo del Haya en Valdeolea, cedidas al obispo en $1194 .{ }^{97}$ En cualquiera de los casos por la descripción de sus bienes se puede deducir que también constituían centros de explotación de tierras y hombres. ${ }^{98}$

Como se ha podido observar entre los bienes entregados a los obispos cabe destacar los monasterios completos o portiones de los mismos. Configurarán la parte más sustancial del patrimonio episcopal en Cantabria. Eran importantes porque como "monasterios propios» casi siempre de los monarcas, constituían, en el momento en el que eran cedidos al obispado, centros señoriales, complejos productivos e institucionales que incluían un campesinado dependiente $^{99}$, unidades de producción de diferentes bienes y

92 ¿Se puede relacionar la denominación de ecclesia cuando realiza funciones parroquiales como iglesias monásticas?

93 Garrido Garrido 1983a: $\mathrm{n}$ ㅇ‥

94 Ibídem: n.o 58. A pesar de esta cesión de collazos, en 1352 no aparece registrado ningún vasallo del obispo de Burgos en Ruerreros. Martínez Díez (ed.) 1981: 489.

95 Garrido Garrido 1983a: n.o 110. Iglesia parroquial hoy de Helguera de Iguña. En 1421 los frutos, granados y menudos, de los préstamos de esta iglesia fueron arrendados a Gonzalo de Mediaconcha. A.C.B. RR- 5.Fol.3.

96 Ibídem n.o 165. Santa Cruz en esta ocasión se denomina eclesia mientras que en la dotación inicial se refiere a un monasterio y se puede comprobar que en efecto era un monasterio. El lugar de Santa María de Valdeprado aparece en 1352 como solariego de los Villalobos. Martínez Díez (ed.) 1981: 508.

97 Garrido Garrido 1983b: n.o 322. La entrega excluía la décima parte de la iglesia que era de San Pedro de Cervatos y otra parte que pertenecía a los nietos del donante. Parece que, en realidad, se trataba de un monasterio dedicado a San Pedro en el paraje Cuesta de San Pedro en Castrillo, donde aún persisten restos de tumbas de lajas. Los frutos de los préstamos del monasterio de San Pedro fueron arrendados en 1424 a Diego López de Arenas. A.C.B. RR- 5. Fol. 266-267.

98 Aunque en la pesquisa del Becerro ya no consta que en ese lugar, Castrillo del Haya, el obispado mantuviera ningún vasallo. Martínez Díez (ed.) 1981: 453.

99 En tanto que incluyen, en muchas ocasiones, a los collazos. Respecto a la condición de los collazos que aparecen en la documentación burgalesa objeto de este estudio parece que pueden ser considerados como campesinos dependientes al frente de pequeñas explotaciones o instalados en solares, más que, como sugiere Martínez, criados domésticos asimilados a siervos. Martínez García 2007: 254. Posteriormente en el siglo XIV se hace referencia explícitamente a los vasallos. beneficiarios de derechos de pasto en los montes, fuentes, etc. circundantes, que ya ejercían funciones de ordenación socio-económica como ejes de articulación política. ${ }^{100} \mathrm{Y}$ que constituían centros de recepción de renta feudal, ya fuere la procedente de las rentas agrarias o de las que expresaban el poder señorial sobre sus respectivos collazos y vasallos, la renta señorial. ${ }^{101}$

Se puede advertir ciertas semejanzas estructurales en los monasterios cedidos, algunos aparecen delimitados por "términos antiguos» constituidos por unidades básicas de explotación y extensiones incultas, con decanías, iglesias, granjas... que a su vez articulan unidades menores, con obediencias y con collazos, de manera que cada monasterio «vertebra la explotación directa o indirecta, de las diversas unidades que componen su patrimonio». ${ }^{102}$ La anexión de estos monasterios comportaba siempre la incorporación de sus bienes (tierras, viñas, prados, pastos, molinos, pesqueras, huertos, dehesas, derechos de pasto) y de sus collazos o solariegos, en definitiva hombres dependientes. Con este tipo de donaciones se ratifica de nuevo que los monarcas delegaban o compartían con la iglesia de Burgos centros señoriales de realengo que, en algunos casos, se sabe que habían sido gestionados, anteriormente por laicos. ${ }^{103}$

\section{Otros bienes}

Los obispos de Burgos recibieron también otro tipo de bienes como villae, palatio, domos, divisas, heredades o ganado. Se sabe que al menos desde el año 1182 la villa de Torres, próxima a Torrelavega, pertenecía al obispado burgalés, lugar del que, todavía en 1352, se afirma que era abadengo del obispo de Burgos. ${ }^{104}$ Y por concesión en 1168 de Rodrigo González de ¿Ceballos? ${ }^{105}$, alférez de Sancho III y de Alfonso VIII, la iglesia de Burgos recibió un palatio en Los Carabeos, partido judicial de Reinosa, con todas sus pertenencias. ${ }^{106}$

La cesión de divisas se inaugura en 1071 cuando la condesa Momadona entrega a la iglesia episcopal de Santa María de Sasamón, que pertenecía a Burgos, la divisa que había heredado de su madre en Los Carabeos. ${ }^{107} \mathrm{Y}$ en 1099 Elvira Hañez y sus hijos donaron al obispo y cabildo burgalés varios solares con divisas en Bricia y en el entorno

100 Como focos de control, «islas de autoridad», de las que habla Martín Viso 2007: 259-260.

101 Véase al respecto, Estepa Díez 1993: 373-425.

102 Véase al respecto Pérez 2012: 811.

103 Este fue el caso del monasterio de San Miguel de Cejancas y el de San Julián, anteriormente en manos de Martín Peláez. Garrido Garrido 1983a: n. 178.

104 Según se conoce por la bula papal de enero de 1182. Ibídem: n.으 220. Martínez Díez (ed.) 1981: 207.

105 Sobre este individuo vinculado primero a Rodrigo González de Lara puede verse González de Riancho Colongues 2010: 42-45.

106 Garrido Garrido 1983a: n.o 176. El término palatium parece que puede incluir un conjunto de bienes y derechos diversos. Martínez García 2007: 265. O un centro de gestión y explotación de un dominio. A pesar de que, en 1352 el lugar de Los Carabeos, era registrado como behetría. Martínez Díez (ed.) 1981: 538. En el siglo XVI el obispo de Burgos percibía el cuarto de los diezmos y disponía de unas tierras en varios lugares entre ellos, unas «detrás de la iglesia donde estaban los palacios». Huidobro y Serna 1934: n.o 127: 111.

107 Garrido Garrido 1983a: n.o 23. 
de Reinosa. ${ }^{108}$ En 1093 es un matrimonio el que entrega un solar con su heredad y con su divisa en el lugar de San Jorge de Toranzo ${ }^{109} \mathrm{y}$, cuatro años más tarde, la Deo devota Fronilde cede una divisa en Fuentesevir en el mismo valle. ${ }^{110}$ Territorio en el que, como ya se indicado, el obispado recibió de Alfonso VII, unos años más tarde, el monasterio de San Jorge (Santiurde). ${ }^{111}$ La sede burgalesa también incorporó en 1101 unos solares y divisas en varios lugares del valle de Carriedo a la vez que recibía la cuarta parte del monasterio de Santa María de Tezanos en el mismo valle. ${ }^{112} \mathrm{Y}$ en 1168, del hijo del conde Rodrigo recibió las heredades que aquél tenía en el alfoz de Cudeyo; casas, heredades pobladas y yermas, en Bedia, en Elechas, en Ambojo, Muslera, en Pontejos y en Gajano. ${ }^{113}$ En 1185 es el conde Gonzalo Rodríguez el que entrega a Burgos su propia heredad en Ruerreros y Riopanero, en Valderredible. ${ }^{114}$

Cuando la documentación habla de hereditates de forma genérica resulta difícil apreciar sus características. Se puede aludir tanto a bienes muebles como casas, o a inmuebles de muy diversa composición: desde solares a tierras de cultivo. Ahora bien la referencia a heredades pobladas y sin poblar parece que indica que abría la posibilidad al beneficiario, en este caso al obispado, de promover populaturas y crear nuevas explotaciones campesinas bajo su estructura señorial.

Ha de mencionarse también que en algunas de las donaciones se incluyen, entre los diversos bienes cedidos, casas, hórreos, molinos, pesqueras... ${ }^{115}$ tal y como se ha enumerado al hablar de la recepción de monasterios.

Desde la propia restauración de la sede episcopal, los obispos de Burgos debían de contar con un tipo de bien muy apreciado: el ganado, tanto el propio como el de los monasterios e iglesias que configuraron su patrimonio fundacional. En otro caso no se entenderían los privilegios de aprovechamiento ganadero que recibieron desde el comienzo de su andadura; como ejemplo en un texto atribuido a Sancho II, se les otorgó licencia para que sus rebaños pudieran permanecer, pacer y tener sus cabañas en algunos montes de Cantabria. ${ }^{116}$ Aunque son muy escasas las referencias al ganado en las donaciones conservadas existe una pista que puede indicar la importancia de la explotación pecuaria en la economía episcopal, y es la mención, muy habitual, de la trasmisión de derechos de pasto en los lugares donde

\footnotetext{
108 Ibídem: n. 68 .

109 Ibídem: n.o 50 .

110 La divisa incluía un solar con casas edificadas, con su heredad culta e inculta, con árboles pomíferos plantados, con pastos en montes y en llanuras, con fuentes, ríos, etc. La divisa procedía de su madre y estaba excusada ab omni iugo vel fisco regalium ita sicuti eam avi mei possiderunt. Ibídem: n.으. 63 .

111 En concreto en el año 1128. Ibídem: n. 110.

112 Ibídem: n.o 72. Un caso un poco más confuso respecto a la consideración de donación pues la donante recibe en roboración XVIII dineros.

113 Ibídem: n.o 174. Pedro Rodríguez el protagonista ¿Hijo de Rodrigo González de Lara?

114 Garrido Garrido 1983b: n. 254.

115 Ibídem: n. 322.

116 Garrido Garrido 1983a: n.o 22. Concedo vobis Symeoni episcopo, ut toto vestro ganado, sive illos propio de illa sede quam et de omnibus vestris monasteriis et obedientiis, que habetis vel habere potueritis, habeam plenariam licentiam de pascere et de stare et tenere suas capannas per omnes meos montes...
}

recibían algún tipo de bienes. Tan sólo se registran dos ocasiones en las que el prelado burgalés es receptor directo de especies ganaderas. En 1194, cuando el obispo don Marino recibe la donación de dos iglesias y quince vacas y bueyes, además de otros bienes muebles. ${ }^{117} Y$ en 1200 , cuando el noble Diego González entrega sus bienes procedentes de la herencia de su madre en el valle de Piélagos y además añade que el obispo pueda disponer de la décima de todas las vacas que le llevaban varios ganaderos (¿collazos, aparceros?), reservándose disponer del resto del servicium illarum vaccarum. ${ }^{118}$

Tras las descripciones que anteceden resulta conveniente presentar algunas consideraciones generales. La mayoría de las donaciones se producen entre la segunda mitad del siglo XI y el siglo xII y además se advierte, respecto a la distribución geográfica de la propiedad de la iglesia de Burgos en Cantabria, una polarización en ciertas áreas concretas, ¿«manchas de leopardo»?, áreas en las que el obispado puede controlar mecanismos de gobierno y concentración de rentas ? $^{119}$ En este sentido es interesante constatar el esfuerzo episcopal en afianzar sus propiedades y derechos en determinados ámbitos, entre los que cabría destacar el entorno del camino real hacia Burgos desde finales del siglo xII.

\section{De los collazos a los vasallos. Privilegios reales y exenciones diversas}

Como se ha descrito en páginas anteriores la recepción de monasterios e iglesias, en muchos casos, suponía la incorporación a la iglesia de Burgos de hombres dependientes, de $\operatorname{collazos}^{120}$, sentando las bases de la constitución de un señorío, como en las propias fuentes se denomina, de abadengo: el señorío episcopal de Burgos. En principio es posible pensar que las condiciones de los collazos, tanto de los que vivían en sus propias tierras como los asentados en solares para poblar de los monasterios, no variasen mucho respecto a las precedentes, a las que soportaban anteriormente en el realengo. Quizás el obispado a través de los monasterios incorporados y sujetos a su señorío tuviera mayor capacidad para ejercer un control más eficaz sobre los campesinos dependientes.

En los casos en los que se pueden conocer un poco mejor las condiciones de los vasallos de los obispos de Burgos se sabe que aquéllos gozaban de ciertos privilegios y que a la vez estaban comprometidos al abono periódico de determinados tributos. Empecemos por indicar los primeros. En 1352 se afirma categóricamente que los vasallos de los prelados burgaleses no pagaban yantar ni fonsadera al rey por previlligios que tenía la iglesia de Burgos. ${ }^{121} \mathrm{Y}$ en efecto, sobre el yantar se conoce que los vasallos del obispo estaban liberados del pago de ese tributo al rey, al menos desde finales del siglo XIII; en 1286, el merino mayor de Castilla

117 Garrido Garrido 1983b: n.o 322. El protagonista de la donación cede también para después de su muerte cabras, puercos, gallinas etc.

118 Ibídem: n.ㅇ 349.

119 Larrea Conde 2007: 334.

120 Campesinos asentados en solares. La propia expresión de solares poblados desde el siglo XI englobaba a campesinos dependientes.

121 Martínez Díez (ed.) 1981: 467. 
reconoce que los monasterios de Latas y Cudeyo ${ }^{122}$ estaban exentos de ese tributo. ${ }^{123}$ No obstante, fue necesario proceder a una investigación para que Sancho IV, en 1292, ordenara que no se les solicitara semejante impuesto al obispo ni a sus vasallos. ${ }^{124} \mathrm{~A}$ pesar de esta recomendación los privilegios se infringían pues se requería constantemente la confirmación real. ${ }^{125}$ En julio de 1334 fue el monarca Alfonso XI quien ratificó la exención hecha por sus predecesores sobre que los vasallos del obispo y de la iglesia no tenían que proporcionar cada año el yantar salvo ende quando nos la dieren en convite. ${ }^{126}$ Esta reiteración de pesquisas y confirmaciones revela que, en muchas ocasiones, estos privilegios se conculcaban, no se respetaban y se exigían incluso por la fuerza. Y así se entiende que desde el último tercio del siglo XIII fueran constantes las quejas de los obispos sobre los agravios que estaban sufriendo sus vasallos por parte de ricosomes, caballeros, hidalgos y oficiales reales. ${ }^{127}$

Es posible que la exención del fonsado y fonsadera de los vasallos de la sede burgalesa provenga de la concesión de Sancho II cuando establece que nullus sit ausus inquietare eos pro fossato at anubda sive labore castelli pro aliquo fiscale vel regale servitium. ${ }^{128}$ En cualquier caso constituye un privilegio similar a los que el monarca Alfonso VI otorgó en $1075 .{ }^{129}$ En 1285, en una intervención de Sancho IV, se recuerda a los merinos y recaudadores de la fonsadera que los vasallos del obispo e iglesia de Burgos nin deven dar fonsadera nin yr en fonsado. ${ }^{130}$ Confirmación que de nuevo se reitera en agosto y en diciembre de 1288 en la que se prescribe la obligación de retornar lo que por ese concepto se hubiera tomado indebidamente. ${ }^{131}$ Cuatro años más tarde de nuevo es el monarca el que ratifica la exención frente a la demanda del alcalde de Burgos, cogedor de la fonsadera, de que los vasallos del obispo abonaran este tributo. ${ }^{132}$

122 No se sabe exactamente el monasterio al que se refiere en Cudeyo. Puede ser alguno en los que el obispado tenía alguna participación como por ejemplo el de Bedia o el de Gajano. Puede ser que la referencia al monasterio del obispado en Cudeyo se refiera alguno ubicado en Hermosa, pues en el Becerro de las Behetrías se dice que «ese logar era solariego, behetría y abadengo del obispo de Burgos y del abad de Oña». Martínez Díez (ed.) 1981: 573, aunque la iglesia parroquial lleva la advocación de San Martín. O también puede referirse a la iglesia de Santa María del valle de Cudeyo ¿Santa María de Miera? considerada en el Libro de Apeos de la Dignidad Episcopal, cámara del señor obispo donde se afirma que se recogían todos los diezmos de varias iglesias. Huidobro y Serna 1934: n.o 129: 302.

123 Pereda Llarena 1984a: n.o 215. El territorio de Cudeyo estuvo bajo el poder de la monarquía navarra en el siglo XI y todavía en el siglo XII era reclamado por los navarros.

124 Ibídem: n.o 270 y 292 . Ese mismo día confirmó una carta suya declarando exentos de yantar al obispo, al cabildo y a los vasallos de ambos. Ibídem: n.o 270, 293 y 294.

125 Ibídem: n.o 292, 293 y 294. En 1299 fue Fernando IV el que de nuevo confirmó el privilegio. Ibídem, n. 9330 y 331.

126 A.C.B. Vol. 2, p. 2, f. 8.

127 Ibídem: n.o 193. Los obispos siempre buscaron el amparo de la justicia regia en sus disputas con la aristocracia. Reglero de la Fuente 2006: 243.

128 Garrido Garrido 1983a: n.o 22. Aunque este texto no ofrezca demasiadas garantías.

129 Ibídem: n.o 26, 27.

130 Pereda Llarena 1984a: n.o 201.

131 Ibídem: n.o 225 y 229. De hecho se requirió la intervención del alcalde del rey para que no se prendiese a los vasallos del obispo ni de su iglesia por razón de la fonsadera. Ibídem: n.o 230.

132 Ibídem: n.o 271.
Hubo de recurrirse al abad de Valladolid para que ordenara al recaudador que no la demandara y que devolviera lo que se había exigido por ese concepto. ${ }^{133}$ Parece evidente que era urgente ante las necesidades de la guerra, en concreto como expresa el propio monarca; para levar los fierros de los engenios e las armas que nos mandamos fazer en Castiella para la hueste de Tarifa, percibir este tributo. Aunque con ello hubiera de transgredirse los compromisos de los privilegios ${ }^{134}$ e incluso recurrir a medios más expeditivos, lo que motivaba constantes quejas ante los monarcas y provocaba frecuentes conflictos. ${ }^{135}$ En 1294, es el propio rey el que ordena a los recaudadores que respetaran los privilegios de los vasallos de Burgos y a la vez se conoce que había sido el camarero mayor, oficial regio, quien había exigido los pagos. ${ }^{136}$ Muestras de ese juego permanente de la monarquía de conculcar derechos por la pasividad o con la connivencia de sus funcionarios reales que procedían a cobros indebidos, (incluso exigidos con cierta violencia) ${ }^{137}$, aparecen en el Becerro de Behetrías ${ }^{138}$ a la vez que, desde la Cancillería real se emitían reiteradas confirmaciones de los privilegios.

Los vasallos del obispo gozaban de algún otro privilegio especial como el portazgo. Ello se deduce, en principio, de la reclamación que llevan a cabo los vasallos del obispo en Latas cuando defienden en 1274 que, como todos los vasallos del obispo en el reino de Castilla y de León, no se les exigiese el pago de portazgo. ${ }^{139}$ Parece que los vasallos del obispo y de la iglesia de Burgos estaban exentos de semejante impuesto desde la época del rey Alfonso IX $\mathrm{X}^{140}$, pero como en muchos otros de estos privilegios la exención requirió de confirmación en sucesivas ocasiones. ${ }^{141}$ En 1283, es el infante don Sancho a instancias del obispo el que recuerda que no se les puede demandar ese tributo y que se penalice al que lo haya exigido sin fundamento. ${ }^{142}$

La sede burgalesa participó de la décima parte de todos los portazgos de la Corona por privilegio real de Alfonso VII. Respecto a si el obispado de Burgos gozó de algún privilegio para disfrutar o participar en los derechos de portazgo cobrados tradicionalmente en Pie de Concha parece que la

133 Ibídem: $n .9273$ y 279.

134 Ibídem: n.ㅇ 283.

135 Pereda Llarena 1984b: n.o 299.

136 Ibídem: $n$. 298 . Tres días más tarde es la reina la que ordena a los recaudadores que respeten los privilegios del obispo y de sus vasallos y en Octubre de ese mismo año es de nuevo Sancho IV el que lo ratifica. lbídem: n.o 299, 303.

137 Oceja Gonzalo 1986: n o 410. En abril de 1292 Sancho IV confirma la exención de fonsado y fonsadera, al mes siguiente insiste al recaudador de la fonsadera de que no tome nada a los vasallos del obispo por ese concepto. En 1299, en la confirmación de Fernando IV, se vuelve a recordar a los recaudadores que no demanden a los vasallos del obispo fonsadera nin los preydren nin los afinquen porque vayan a fonsado. Pereda Llarena 1984a y 1984b: n.o 271 y 273, 334, 337. Este no fue el final del enfrentamiento; las confirmaciones de exención de la fonsadera se reiterarán durante todo el siglo XIV.

138 Martínez Díez (ed.) 1981, T.II: 207-191. En concreto cuando los del lugar de Torres y Mazcuerras afirman que se la hacían pagar por la fuerza desde el cerco de Algeciras.

139 Pereda Llarena 1984a: n.ㅇ 117.

140 Esta información se contiene en un documento de Alfonso XI, quien a petición del obispo don García confirma la exención de portazgo a favor de los vasallos del obispo. A.C.B. Vol.2, p. 2, f.38.

141 Pereda Llarena 1984a y 1984b: n. 194, 195, 332.

142 Pereda Llarena 1984a: n.o 178. 
respuesta es negativa, a pesar de que desde 1185 el obispo era propietario del monasterio de Cillaperriel (Bárcena de Pie de Concha) y en el siglo xIV se reconocía ese lugar como propio de la iglesia y del obispo de Burgos, según se constata en el propio Becerro. ${ }^{143}$ En esa época, se confirma la existencia en ese lugar de un centro de control del tránsito de paños y metales y se atribuyen los derechos al rey, aunque en ese momento concreto el monarca compartía los derechos de peaje con el señorío de la Vega y el abad de Santa María de Aguilar de Campoo. Por la información recogida en el Apeo de 1404 se sabe que el lugar concreto donde se cobraba era en un castillo aislado en el monte ${ }^{144}$, posiblemente el castillo de Cobejo. En el siglo Xv los derechos eran percibidos por D. $\underline{a}$ Leonor de la Vega; de hecho en el inventario de sus bienes se registra la cantidad que se había cobrado en el año de $1432 .{ }^{145}$ En el siglo XVı la villa de Pie de Concha continuaba siendo del obispo quien disponía de unos palacios junto a la iglesia, tenía la jurisdicción sobre sus vasallos, los vecinos de la villa, confirmaba el alcalde y merino elegido por la villa y estaba en posesión de numerosos solares junto al Camino Real que atravesaba la villa. ${ }^{146}$

A su vez, los vasallos tenían una serie de obligaciones para con el rey y para con el señor obispo en su condición de señor feudal, aunque únicamente son conocidas a partir del siglo XIV. A los monarcas los vasallos de la iglesia de Burgos les abonaban, en general, el impuesto de servicios y monedas y la martiniega, aunque esa circunstancia no impidiera el que, en 1334, Alfonso XI, concediera a don García, obispo de Burgos, la mitad de los serviçios e ayudas que ovieren a dar a nos e a los reyes que vernan después de nos los vuestros vasallos e de vuestra iglesia. ${ }^{147}$

$Y$ al señor obispo en el siglo XIV los vasallos tenían que abonarle la infurción ${ }^{148}$ cada año por San Martín, generalmente por cotización según unidad familiar, bien por vasallo o por cada solar ${ }^{149}, y$, en alguna ocasión aislada, mediante el pago colectivo, es decir, el concejo. ${ }^{150}$ En general este impuesto era efectuado en especie: en trigo o en escanda, o de naturaleza mixta, en especie y en dinero. Los vasallos también estaban obligados a satisfacer el pago del nuncio - de cada uno que fina sin fijos- y de la mañería, impuestos abonados en metálico. ${ }^{151}$ En algunas ocasiones el obispo percibía también la totalidad o una cuarta parte de la martiniega, cobrada siempre en moneda. ${ }^{152}$ Se desconoce si los

\footnotetext{
143 Martínez Díez (ed.) 1981, T.Il: 179-180.

144 González Camino y Aguirre (ed.) 1930. Los derechos de portazgo los percibía entonces D. a Leonor de la Vega.

145 Pérez Bustamante 1979: 341.

146 Huidobro y Serna 1934: n.o 127: 114-117.

147 A.C.B. Vol. 2 p.1. f. 9. Y así se reconoce en 1352 a los vasallos del obispo en Pie de Concha que no pagasen servicios ni monedas. Martínez Díez (ed.) 1981, Il: 179.

148 Sobre la infurción como renta señorial en el Becerro de las Behetrías véase Martínez García 2001: 199-201.

149 Como los vasallos vecinos de Pesquera. Huidobro y Serna 1934: n. $-127: 113$.

150 Este fue el caso del lugar de Torres. Martínez Díez (ed.) 1981. II: 207. Esta característica también aparece en otros ámbitos como por ejemplo en el señorío del cabildo ovetense. Fernández Conde 1993: 150.

${ }^{151}$ Así se recoge en los lugares donde el obispo tenía vasallos, Martínez Díez (ed.) 1981, II: 124, 156, 179-180, 191-192 y 207 y I: 467, $468,469$.

152 Este fue el caso de Torres, Pesquera y Cejancas de Suso. Martínez Díez (ed.) 1981, II: 207 y I: 467, 484.
}

vasallos estaban obligados a satisfacer algún tipo de prestación personal como ocurrió con las vasallos de otras instituciones episcopales ${ }^{153}$, aunque la frecuencia de referencias a sernas próximas a los monasterios e iglesias dependientes del obispado puede llegar a sugerirlo.

Se desconocen las formas que los obispos de Burgos utilizaron en la gestión del patrimonio acumulado por las donaciones. Martínez García afirma que la explotación directa fue la fórmula más propicia para el aprovechamiento de los primeros recursos dotacionales. ${ }^{154}$ En el caso burgalés, es posible suponer que la explotación de los bienes recibidos, prioritariamente de los monarcas, aglutinados en torno a los monasterios o ecclesiae cedidos, se llevase a cabo con campesinos dependientes, los homines o collazos mencionados en las donaciones. Y esto debió ser así tanto para aquellos instalados en tierras propias como para los que poblaban las heredades o solares traspasados, con lo que únicamente se modificaba su condición de collazos de realengo a abadengo, y las rentas que abonaban al rey, como señor feudal, pasaban a ser transferidas a sus nuevos señores, es decir, a los prelados de Burgos.

Las escasas referencias al respecto, mucho más tardías, sugieren que en el siglo XIV, cuando ya se había producido una cierta disminución del poder del obispado sobre los hombres dependientes de su señorío, se recurriera, como en otros señoríos catedralicios, a otros medios como la encomienda o el arrendamiento a censo. Así ocurrió en Mazcuerras que se cedió en encomienda ${ }^{155}$ y como ya se había procedido a disponer en arriendo, por ejemplo, de las tercias de varias villas de Toranzo. En el siglo xv se arrendaron los frutos y rentas de los préstamos de varias iglesias y monasterios entre ellos Santa Leocadia de Helguera, Santa María de Fresno, San Miguel de Cejancas, San Pedro de Castrillo, San Facundo de Silió y San Miguel de Pesquera. ${ }^{156}$ De hecho las heredades que aparecen vinculadas al obispo en el Libro de Apeos del siglo XVI, aparecen, en su totalidad, cedidas a diferentes individuos bajo muy distintas condiciones. En alguna de las cláusulas además del arriendo subsistía aún algún tributo de carácter feudal como la infurción, la martiniega o el tocino el año que hubiere grana en el monte, especialmente en aquellos lugares en los que el señorío del obispo de Burgos había sido más unitario y persistente, como en Cillaperriel o en Pesquera. ${ }^{157}$

Además de los privilegios reseñados para los vasallos del obispado, la Catedral de Burgos recibió, desde la creación de la sede, derechos de pasto y pesca. Desde el año 1068, por concesión del rey Sancho II de Castilla, los rebaños del obispado podían acceder libremente y aprovecharse de la madera en algunos de los montes de los valles de

\footnotetext{
153 Por ejemplo en Zamora, Martín 1978: 90-93.

154 Martínez García 2007. 252. Según este mismo autor, el abadengo episcopal hubo de optar por acercarse después al mundo urbano, al comercio, al disfrute de rentas regias de tipo jurisdiccional y al arrendamiento de sus tierras de plena propiedad.

155 Dan al señor que los tiene en encomienda. Martínez Díez (ed.) 1981, II: 191-192.

156 A.C.B. RR-5. fol. 3 y 266-267. RR-6. fols.: 175 y $232 v-233$.

157 En esos sitios es muy frecuente que las heredades estén ubicadas en lugares denominados sernas. Huidobro y Serna 1934: n.o 127: 113-117.
} 
Cantabria. ${ }^{158}$ También la sede episcopal obtuvo del mismo monarca licencia para pescar por todos los piélagos y dehesas y puertos marinos del cantábrico; en Santa María del Puerto, en el puerto de Santander, en el de San Martín de la Arena entre otros. ${ }^{159}$

¿Hasta qué punto ejercían estos derechos y se respetaban semejantes privilegios? En general, se puede deducir que la sucesiva reiteración de confirmaciones indica que las cláusulas de los privilegios se violaban y de ahí la necesidad de solicitar una y otra vez la ratificación de las concesiones. Este puede ser el caso de la confirmación que en 1285 llevó a cabo Sancho IV sobre la libertad de pastos por todo el reino para los ganados del obispo e iglesia de Burgos y de sus monasterios y obediencias sin embargarles ni demandar el montazgo. ${ }^{160}$

Respecto a los derechos jurisdiccionales de los obispos burgaleses se sabe que en algunas concesiones reales de monasterios se añadían privilegios de exención de justicia como en San Jorge de Toranzo o en San Cosme y Damián de Cillaperriel. O como en San Martín de Mazcuerras donde por cesión del monarca Fernando I se reconoce que únicamente era el obispo el que tenía el derecho a percibir de sus vasallos algún tributo real, entre ellos, el homicidio y por ello debía ser satisfecho a la mitra. ${ }^{161}$ En el siglo XVI se confirma que los obispos de Burgos disponían de jurisdicción señorial en lugares como Pie de Concha y Pesquera.

\section{Derechos en los puertos del Cantábrico}

Mención especial requieren los derechos del obispado sobre los puertos marítimos. Fue el monarca Alfonso VIII el que vinculó los destinos del obispado de Burgos con los puertos de la costa de Cantabria al conceder al obispo de Burgos, don Marino, en 1192, el diezmo del portazgo del puerto de San Emeterii íntegro, de todas las mercaderías que accedieren a este puerto indistintamente por tierra y por mar, así como de los otros puertos de obispado excepto en el puerto de Castro Urdiales del que únicamente concedía las décimas de tres productos concretos: de los paños, de las armas y del querambre. ${ }^{162}$ Este privilegio, fue confirmado por los monarcas Alfonso X y Sancho IV, cuando ya se especifica mejor el alcance de la donación (el diezmo de todos los diezmos que nos tomamos en el puerto de Santander e de Castro de Ordiales e de Laredo e de los otros puertos de so obispado...tan bien de entrada commo de salida). ${ }^{163} Y$ fue objeto de frecuentes conculcaciones a juzgar por las sucesivas confirmaciones que requirió. En 1324 Alfonso XI envió una carta a los arrendadores judíos de los diezmos de los

158 Garrido Garrido 1983a: n.ㅇ 22. En concreto en los de Trasmiera, en los del valle de Carriedo y valle de Toranzo, en los de Fluena, ¿Luena?, en los de Cabezón y en Afleca (Valdáliga) hasta la rivera del Deva.

159 Ibídem: n.o 22.

160 Pereda Llarena 1984a: n.o 191.

161 A.C.B. V. 34, fol. 346. No debían pagar homicidio con los hombres de Cabezón ni dar ningún pecho al rey ni conducho a ricohome a no ser al obispo.

162 Garrido Garrido 1983b: n.o 305. En 1124 Alfonso VII había concedido a la iglesia de Burgos la décima parte de todos los portazgos de la Corona Real. A.C.B. Vol.2, p 1.

163 Pereda Llarena 1984a y 1984b: n.o 14, 268 y 311. Ambos monarcas confirmaron al obispo y al cabildo el diezmo de los puertos de la mar. puertos de Castro Urdiales, Laredo, Santander, San Vicente de la Barquera y Rioturbio ordenándoles que respetaran el derecho del obispo y del cabildo de Burgos. ${ }^{164}$ Amonestación que hubo de reiterarse cinco años más tarde a los siguientes arrendadores para que entregaran el rediezmo de los diezmos de los paños y de todas las otras mercaderías que diezmaran anualmente en los dichos puertos. ${ }^{165}$ Para garantizar el cobro el cabildo (porque según parece percibía a su vez la mitad del rediezmo) nombró por su cuenta en junio de 1329 a un clérigo de Castro Urdiales como su propio diezmero para que controlara el tributo en los puertos de Castro, Laredo y Santander. ${ }^{166}$ A pesar de estas medidas cautelares no se consiguió el objetivo de percibir el importe y protagonizó sucesivas reclamaciones frente a los oficiales regios, de manera que de nuevo el monarca Alfonso XI es el que, a petición del obispo don García, se vio impelido a confirmar en 1333 las anteriores concesiones para poder garantizar su cobro. ${ }^{167}$

El destino de los diezmos de la mar de la cornisa cantábrica, una de las rentas más valiosas de la Corona fue enajenada por Enrique IV en 1469 a la familia Velasco, previo compromiso de respetar lo que la monarquía había concedido a instituciones religiosas y otras personas. Parece pues que, a pesar de los problemas, los obispos de Burgos fueron capaces de mantener sus derechos de participación sobre estas rentas reales. De hecho, en 1516, varios testigos confirmaron que «el rediezmo de los diezmos de la mar que en Laredo y en las otras tres villas, San Vicente, Castro y Santander de esta costa que de lo que paga por los diezmos de las cosas que vienen de allende de la mar... pertenecían la mitad al señor obispo y la otra al Cabildo de Burgos». ${ }^{168}$

También Alfonso VIII fue el monarca que concedió en 1181 a los prelados y eclesiásticos de la diócesis de Burgos el que se respetaran sus bienes y la exención de omni posta et facendera et ab omni alterius modi pecta que ad regen pertinet. 169

\section{UNAS CONSIDERACIONES FINALES}

Después del análisis, inevitablemente descriptivo, de los bienes y privilegios que constituyeron el patrimonio episcopal burgalés en tierras de Cantabria, es momento de sugerir algunas reflexiones más que unas conclusiones cerradas.

En primer lugar debe recordarse que el objeto principal de las donaciones recibidas por el obispado burgalés fueron monasterios o ecclesiae, lo que revela que la forma de

164 A. C. B. Vol. 4, p. 2, f. 43.

165 En marzo de 1329 Alfonso XI vuelve a confirmar el derecho del obispo y del cabildo al rediezmo de los diezmos. A.C.B. Vol. 4, p. 2, f. 11.

166 A. C. B. Vol. 4, p. 2, f. 11. Es elegido para este oficio Sancho Martínez, clérigo de Castro Urdiales porque era buen hombre y de buena fama.

167 A. C. B. Vol. 4, p. 1, f. 6. Por este texto se sabe que la iglesia de Burgos primero tenía derecho al diezmo del treintavo que el rey tenía en los mencionados puertos y después al diezmo de los diezmos y para que se pudiera controlar adecuadamente se establece que los que recogen los diezmos por parte de la iglesia y del cabildo pongan su sello en los albalaes de los mercaderes que introduzcan o saquen productos de los puertos.

168 Huidobro y Serna 1934: n.ㅇ128: 213-214.

169 Garrido Garrido 1983a: n. 216. Estas concesiones se pueden justificar por los apuros financieros de este monarca. Serrano 1922: 48. 
articulación del patrimonio regio en esta región, Cantabria, se llevaba a cabo desde centros monásticos que habían ya desarrollado pequeños dominios supralocales. Es conocido que los monasterios o iglesias propias, en este caso del realengo, constituían unos instrumentos de gestión de los dominios de los monarcas como focos de implantación y reproducción señorial que se convertían en "nodos en las redes económicas y sociales definidas por una de las escalas de acción de mayor complejidad ${ }^{170}$, en este caso, la realeza.

Esta circunstancia podría apoyar que ese sistema de organización a través de "monasterios propios» pudo ser un modelo frecuente en la articulación política medieval del territorio de Cantabria. De hecho, en otras zonas, las donaciones de los monarcas a otras sedes episcopales consistían en unidades de organización del espacio como castillos o aldeas caso, por ejemplo, de las transferencias del realengo que recibió la iglesia episcopal de Cuenca, o de las villas concedidas a la sede palentina ${ }^{171}$, lo que puede presuponer la existencia, en aquellos lugares, de patrones diferentes de vertebración del territorio. ${ }^{172}$

La importancia del "monasterio o iglesia propio» en Cantabria, se pone de relieve cuando se conoce su frecuente presencia ${ }^{173} \mathrm{y}$, sobre todo, cuando se observan las vinculaciones entre ellos; la agregación de monasterios o iglesias propias a entidades religiosas ya asentadas, ya fueran de carácter regular monástico o secular de los que existen expresivos ejemplos. Fue de esa manera como se configuraron redes de dominio supralocal sobre el territorio. Uno es el caso de las anexiones, más o menos «espontáneas» ${ }^{174}$, a determinados monasterios regionales como Santa Juliana, Santa María del Puerto o Santo Toribio. ${ }^{175}$ Y otro, las sucesivas incorporaciones de "monasterios propios» a la sede episcopal de Burgos. Ambos ejemplos pueden poner de manifiesto estrategias político-espaciales coyunturales, además del interés de la monarquía en promocionar, en momentos distintos, unas instituciones concretas como puede ser el caso del señorío de Santillana o del obispado burgalés.

¿Qué objetivos se perseguían con el traspaso de estos centros señoriales (gestionados desde monasterios locales dependientes de los monarcas), a la órbita de un obispado que ya tenía reconocida su capacidad como institución episcopal de una diócesis que implicaba directamente a estas tierras? Es evidente que para entender este conjunto de actos reseñados debieron existir múltiples motivaciones tanto por parte de los donantes como de los donatarios. ${ }^{176}$

170 Carbajal Castro 2012: 388.

171 Véase González Díez 1987.

172 Esta es la hipótesis que sugiere Jorge Díaz Ibáñez. Perfectamente justificada por las características de las donaciones y la coyuntura y la voluntad del rey en la colaboración del obispo en la repoblación de tierras recién conquistadas. Díaz lbáñez 2003: 49, nota 31 y 50.

173 Véase al respecto Loring García 1987: 89-120; Martínez Sopena 1991: 323-331.

174 En algún caso perfectamente diseñada, como la licencia otorgada por el monarca para autorizar y reconocer la creación de una iglesia propia y una presura en Toporías con el compromiso de que fuese incorporada posteriormente a un monasterio mayor, en concreto al de Santa Juliana. Jusué 1912: n. LIV y LV.

175 Díez Herrera 2000: 137-157.

176 Véase al respecto las motivaciones que sugiere Susan Wood para explicar la incorporación de monasterios o abadías a los obispados: Wood 2013: 418-433.
Interpretar las estrategias concretas que provocaron estos movimientos resulta una tarea muy compleja de la que apenas puede hacerse alguna sugerencia.

Entre los distintos motivos alegados de forma explícita que justificaban estas entregas se mencionan las siguientes: pro anima ${ }^{177}$, por la remisión de los pecados propios y de sus parientes, por infernum timendo, paradisum conquiriendo ${ }^{178}$, para elegir sepultura en la catedral de Burgos ${ }^{179}$, para subsidio clericorum et pauperum ${ }^{180} \mathrm{o}$ incluso por otros motivos más coyunturales como la gratitud; así ocurrió en 1334, año en el que el monarca Alfonso XI concede al obispo de Burgos un privilegio por haber bautizado personalmente al heredero del trono ${ }^{181}$, o simplemente porque, como reconoce el mismo rey Alfonso XI, Burgos, era «una de las más señaladas iglesias de sus reinos». ${ }^{182}$ No obstante, a pesar de estas manifestaciones, parece obvio entender que existieron otras razones más veladas respecto a por qué las entregas de bienes o derechos se dirigían a unos u otros centros monásticos, o pasaban a manos de algunas instituciones religiosas como ocurrió con el obispado de Burgos. Y a preguntarse también por qué se transferían unos monasterios concretos y no otros. ${ }^{183}$

En las cesiones a las sedes episcopales se pueden proponer a priori razones de disciplina: el impacto de la reforma gregoriana ${ }^{184}$ y la insistencia de la legislación conciliar que culmina en el IV concilio lateranense en que los centros religiosos, monasterios e iglesias propios, dejaran de estar en posesión de laicos. De hecho, desde el concilio de Coyanza a los de Letrán o el Decreto de Graciano y, sobre todo, desde su recepción y difusión en la España cristiana, se insiste reiteradamente en ese sentido. ${ }^{185}$ Pero no fueron las únicas razones. Existen ejemplos de políticas o estrategias regias cuanto menos sospechosas de perseguir unos objetivos mas específicos y coyunturales, como pudo ser el caso del monasterio de Santa Eufemia de Cozuelos. Primero cedido a la sede burgalesa por el monarca Alfonso VI, luego intercambiado por Alfonso VIII por el monasterio de Cervatos, para finalmente ser entregado a la Orden militar de Santiago, donde llegó a convertirse en uno de los prioratos norteños de la Orden.

177 Garrido Garrido 1983a: n.ㅇ 50, 174.

178 Serrano 1935-1936: n.o 55, 90, 130, 139, 144, 223. En algunos casos incluso se especifica de forma más precisa como en 1099 cuando Elvira Háñez entrega a la iglesia de Burgos varios bienes, solares con divisas, por el alma de su hijo Pelayo González. Garrido Garrido 1983a: n.o 68.

179 Garrido Garrido 1983b: n.o 349. Un miembro del linaje de la Vega, que primero había sido abad de Cervatos y posteriormente arcediano de Valpuesta en la iglesia de Burgos dota una capellanía, entre otros bienes, con intención de que si muriese en Burgos fuese enterrado en Santa María, si lo hiciera en Palencia, en San Antolín y si en Santillana, que lo entierren en ese monasterio. Pereda Llarena 1984b: n.o 307, 364.

180 Garrido Garrido 1983a: n. 58.

181 A. C. B. Vol. 2, p. 1, f. 9.

182 A. C. B. Vol. 4, p. 1, f. 6.

183 Puede consultarse García de Cortázar 2012: 255-268.

184 Aunque como afirma Pérez 2013, el proceso no fue lineal ni homogéneo sino que se llevó a cabo a través de prácticas individuales en las que el poder episcopal tuvo que lidiar, en una combinación de presión y negociación con quienes controlaban esas iglesias o monasterios.

185 Durante los siglos XI y XII se produjo un fortalecimiento de las tendencias jerárquicas de la iglesia que tuvo como principal consecuencia la potenciación de la jerarquía episcopal y la estructuración de la institución. 
Estas donaciones pueden, en principio, interpretarse como actos de generosidad, o como formas de acatar las ordenaciones del derecho canónico entre otras. No obstante, para hallar respuestas más convincentes se debería poder averiguar qué implicaban para los obispos esas concesiones. Es posible que la iniciativa partiese de los monarcas -por su propio interés, por presión de la institución eclesiástica o por conveniencia mutua-. De hecho, algunas veces se observa la voluntad de la monarquía en delegar su gestión en la institución episcopal como otra escala de poder más eficaz para articular el territorio en Cantabria. Como hipótesis se puede sugerir que los monarcas no perdían todos los derechos sobre los monasterios cedidos como si de alguna manera se convirtiesen en condominios de realengo y abadengo y de ese modo constituir un sistema más eficaz de generar fidelidades y de imponer otros modelos de gestión de unos bienes compartidos. Los obispos ofrecían en contrapartida ayuda material, militar, colaboración en las campañas -don Pedro, obispo de Burgos murió durante el cerco de Córdoba en 1146-, apoyo político, asesoramiento (consilium) -los obispos curiales o palatinos-, etc. ${ }^{186}$ La fidelización de estas uniones o vinculaciones más o menos coyunturales hacía necesaria la constante confirmación de estas cesiones. De ahí que cuando en 1128 el rey Alfonso VII entrega unos bienes, entre los que se encuentra la iglesia de Santa Leocadia de Valdeiguña y los monasterios de San Jorge en Toranzo y de San Cristóbal de Bárcena en Valderredible ${ }^{187}$, centros tradicionales de realengo, al obispado, esta donación tiene que ser confirmada en 1255 y en 1302 por los sucesivos monarcas. ${ }^{188}$ Confirmando que, de alguna manera, los monarcas con estas cesiones no se desvinculaban de los monasterios donados. ${ }^{189}$ De hecho, en la pesquisa llevada a cabo con motivo de la elaboración del Becerro de las Behetrías en el siglo xIV únicamente se reconocen como lugares del obispo, los de Pie de Concha, Mazcuerras, y Torres ${ }^{190}$ mientras que otros como Santiurde, donde el obispado había recibido el monasterio de San Jorge, aparece entonces como un significativo centro de realengo. ${ }^{191}$ Algo similar ocurrió en Iguña en el siglo XIV, donde es evidente que el realengo se había fortalecido en el valle, cuando en la pesquisa se afirma que los lugares de

186 La implicación del obispo de Burgos en la guerra civil entre Urraca y Alfonso le hizo perder su sede. Reglero de la Fuente 2006: 240. Para conocer la colaboración de los obispos véase Ayala Martínez 2014 2015: 41-106. Recuérdese al respecto el papel del obispo don Mauricio en la corte de doña Berenguela. Serrano 1922: 47. La proximidad a los monarcas castellanos de algunos prelados burgaleses estuvo asegurada por su presencia en la cancillería regía. Guijarro González 2008: 276.

187 Garrido Garrido 1983a: n.o 110.

188 Pereda Llarena 1984a y 1984b: n.o 10, 371.

189 Algo similar ha observado Mariel Pérez en la transferencia de iglesias y monasterios propios en ese caso de la aristocracia, a determinados establecimientos religiosos. Pérez 2012: 815-816. Circunstancia que ya había sido puesta de relieve en González Díez 1987: 300.

190 Martínez Díez (ed.) 1981, T. II: 179, 191, 207. En el Apeo de 1404 tan solo el lugar Pie de Concha es reconocido propio de la iglesia de Burgos, los demás Mazcuerras o Torres solo se hace referencia a heredad de la iglesia. González Camino y Aguirre (ed.) 1930: 98, 38-39, 46.

191 En ese momento eran lugares del rey: Santiurde, Esponzués, Aés, Quintana, Cillero (San Andrés de Prases), Corvera, Villegar de Toranzo... Martínez Díez (ed.) 1981, T. II: 191, 196, 201, 203, 204, 206. En el Libro de Apeos de 1515-16 el obispo percibía el tercio de la iglesia de San Jorge de Santiurde, pueblo del arciprestazgo de Pagazanes, Huidobro y Serna 1934: n.ㅇ 128: 208.
Pujayo, Cillaperriel, la Serna, etc. eran solariegos del rey. ${ }^{192}$ $Y$ sin embargo esta circunstancia no impidió que en el siglo XVI, fuese el obispo el que disponía de jurisdicción civil y criminal, horca, cepo y cadena y percibiese los tercios pontificales de las iglesias de esos lugares. ${ }^{193}$ Se refuerza así la impresión de que los monarcas o no perdían del todo sus derechos con sus concesiones a la sede de Burgos o los recuperaban y en cualquier caso, oscilaban en delegar su gestión en la díscola nobleza o en las sedes episcopales.

Respecto a los intereses del obispado parece que pueden quedar claro varios objetivos. En principio, el interés en la acumulación territorial que suponía la incorporación de esos monasterios del realengo y en la posibilidad de incrementar su patrimonio como centro receptor de legados y donaciones y como agentes señoriales en el desarrollo de fuentes de renta y de servicios, en definitiva en la construcción de un poder señorial. Además cabe pensar en la posibilidad que se abría al obispado, como vía de fortalecimiento de las competencias de la diócesis, de configurar entidades parroquiales a partir de los monasterios e iglesias monásticas recibidas. Es decir, de procurar la transformación de templos de sesgo privado y de naturaleza jurídica confusa, que podían estar desempeñando algunas de las funciones pastorales (bautismo, enterramiento, liturgia sacramental...), ajenas al ius del obispo, en iglesias parroquiales integradas en la red del encuadramiento diocesano. La concentración de donaciones recibidas en el siglo XII coincide con la importancia que alcanza el obispado de Burgos en esa época. ${ }^{194}$ Es la época de construcción de las fábricas románicas más significativas de Cantabria; iglesias especialmente vinculadas al obispado como es el caso de Cervatos, Silió, Pujayo, Cillaperriel, entre otras que de alguna manera hacen pertinente la pregunta de quién promovía y financiaba esas empresas de considerable envergadura y cuya respuesta es, evidentemente, que los que querían asegurarse una distinción jerárquica bien visible. Es la época también en la que se detecta un incremento notable de actos de consagración de iglesias con la imposición de la entrega de tercias ${ }^{195}$, como la de San Cosme y San Damián, la de 1132 de San Lorenzo de Pujayo, la de Santa Eulalia de Somballe en 1167, la del obispo burgalés Gómez en Pesquera, o la del Santa Olalla de Valdeolea en 1174 ... Manifestaciones todas ellas de la activa intervención de los obispos, que unidas a la construcción e instalación de pilas bautismales románicas como la de Castillo Pedroso en Toranzo, o la de San Vicente de León en Iguña, entre otras ${ }^{196}$ revelan el fortalecimiento de la institución episcopal y el incremento de iglesias parroquiales en las cuales el obispo percibe ya todos sus derechos. Este avance en el reconocimiento de las competencias episcopales debió fortalecerse con el apoyo monárquico a la vez

192 Martínez Díez (ed.) 1981, T. II: 216.

193 Huidobro y Serna 1934: n.ㅇ 127: 114-115.

194 El obispado de Burgos se benefició del apoyo papal a través de los once privilegios que recibió desde finales del siglo XI y a través de los concilios y legados pontificios. Véase al respecto Reglero de la Fuente 2006: 255-261.

195 En 1099 el obispo García de Burgos impuso la entrega de tercias como condición para consagrar una iglesia. Garrido Garrido 1983a: n. 67.

196 González Echegaray 1974: 203. También en otros lugares; en Villasuso, San Martín de Quevedo, Somballe, Cañeda... 
que los reyes se beneficiaban del poder que desplegaba el obispo en tierras de Cantabria.

Adicionalmente, la posesión por parte del obispado de bienes ubicados en valles generosamente dotados de montes bravos, de densos bosques, como fue el caso de los valles de Carriedo y el de Toranzo, con una potencialidad ganadera muy significativa, permitía a los obispos el acceso de sus cabañas ganaderas a los pastos estacionales. El único problema es que constituían valles de mucho interés también para la monarquía por ser lugares muy apropiados para las cacerías reales. De hecho algunos de los habitantes de estos valles servían en las monterías reales. ${ }^{197}$ Pero, sobre todo, por los derechos derivados de correr los montes, es decir de cobrar el montazgo: -tomar un cerdo de cada manada de puercos... que de fuera del valle viniese a comer a sus montes-, y de la achería (facultad para cobrar al leñador que no fuera vecino del valle y se lo encontraran practicando su oficio). ${ }^{198}$ Tributos vinculados tradicionalmente a la monarquía que, únicamente por graciosa concesión podían pasar a ser percibidos por algunos titulares de señoríos laicos.

Mención aparte merece el interés en disponer de aprovisionamiento de sal que sin duda estimuló la incorporación al obispado del realengo gestionado desde San Martín de Mazcuerras. Debe recordarse al respecto que desde finales del siglo XI, el obispado se garantizó este recurso a través de las tercias percibidas en Udías. ${ }^{199}$

La tendencia general del poder ejercido por el señorío episcopal de la iglesia de Burgos parece que alcanza su punto álgido en los siglos XII y XIII, época que coincide con el proceso de mayor definición de la red parroquial y con el incremento del control de muchos de sus derechos. A partir de esa etapa su poder señorial fue disminuyendo, posiblemente cediendo a la presión de nobles locales vinculados a las grandes familias castellanas como revela la pesquisa de $1352 .{ }^{200}$ De hecho, los centros monásticos que el obispado llegó a disponer en tierras de Cantabria tuvieron distintas trayectorias y destinos. Unos retornaron al patrimonio real, como fue el caso de Cervatos, otros parece que la comunidad monástica acabó desapareciendo y sus iglesias monasteriales se transformaron en parroquiales sujetas al régimen del obispado. Este último pudo ser el caso de San Martín de Mazcuerras, de San Facundo de Silió, de San Cosme y Damián, de Bedia o de Gajano. Otros monasterios dieron lugar a sedes de algunos de los arciprestazgos de la diócesis de Burgos en la Edad Media como Latas, Muslera, Fresno, Pesquera o Cillaperriel y sentaron las bases de la vertebración del territorio eclesiástico en Cantabria. Esta disminución progresiva de su dominio sobre los hombres fue simultánea con el aumento de la nómina de parroquias aldeanas que satisfacían sus impuestos correspondientes al obispado a la vez que, como sugiere Martínez, el interés

197 Los habitantes de Tezanillos, los de San Andrés de Vega servían con los cuerpos e canes cuando enviaban a llamarles para marchar en son de montería. González Camino y Aguirre (ed.) 1930: 78, 81.

198 González Camino y Aguirre (ed.) 1930: 78-79, 91,97. En 1404 se afirma que el producto del montazgo en Pie de Concha podía ascender a 4 o 5.000 maravedíes. González Camino y Aguirre (ed.) 1930: 102.

199 Desde 1099 el obispado contaba con una participación de un pozo de sal en Cabezón. Garrido Garrido 1983a: n.o 67.

200 Esta tendencia a la disminución de vasallos a favor de la behetría o del solariego se observa por ejemplo en Silió. Martínez Díez (ed.) 1981, T. II: 156. del obispado se orientaba hacia otros objetivos en los que de nuevo podía haber un interés compartido con la monarquía como pudo ser el control de vías de comunicación y los derechos vinculados al tráfico mercantil entre los puertosvillas de Cantabria y la meseta castellana. De hecho en el siglo xIV las rentas de los puertos constituía una de las partidas más significativas de los ingresos del cabildo. ${ }^{201}$

\section{FUENTES Y BIBLIOGRAFÍA UTILIZADA}

Apeo del Obispo 1515-1516. Archivo Capitular de la Catedral de Burgos Libros redondos. Cuadernos de contabilidad Capitular 1.

Escagedo Salmón, M. 1926. Privilegios, escrituras y bulas en pergamino de la Insigne y Real Iglesia Colegial de Santillana. Santoña: Imprenta editorial del Dueso.

Garrido Garrido, J. M. 1983a. Documentación de la Catedral de Burgos (804-1183). Burgos: Ediciones J. M. Garrido Garrido.

Garrido Garrido, J. M. 1983b. Documentación de la Catedral de Burgos (1184-1222). Burgos: Ediciones J. M. Garrido Garrido.

González Camino y Aguirre, F. (ed.). 1930. Las Asturias de Santillana en 1404. Según el Apeo formado por orden del Infante don Fernando de Antequera, Santander.

González González, J. 1986. Reinado y diplomas de Fernando III. Córdoba: Monte de Piedad y Caja de Ahorros.

Huidobro y Serna, L. 1934. "Señoríos de los Prelados Burgenses: Fortalezas y palacios a ellos anejos». Boletín de la Comisión Provincial de Monumentos Históricos y Artísticos de Burgenses 13/46: 12-20.

Huidobro y Serna, L. 1954. "Señoríos de los Prelados Burgenses, Fortalezas y palacios a ellos anejos. Iglesias». Boletín de la Institución Fernán González, 33/127: 107-117.

Jusué, E. 1912. El libro de Regla o Cartulario de la antigua abadía de Santillana del Mar. Madrid.

Martínez Díez, G. (ed.) 1981. Libro Becerro de las behetrías. León: Centro de Estudios e Investigación San Isidoro.

Oceja Gonzalo, I. 1986. Documentación del monasterio de San Salvador de Oña (1285-1310). Burgos: Ediciones J. M. Garrido Garrido.

Pereda Llarena, F. J. 1984a. Documentación de la Catedral de Burgos (1254-1293). Burgos: Ediciones J. M. Garrido Garrido.

Pereda Llarena, F. J. 1984b. Documentación de la Catedral de Burgos (1294-1316). Burgos: Ediciones J. M. Garrido Garrido.

Polanco Pérez, A. 2008. La catedral de Palencia en el siglo XV (14021470). Poder y comportamientos sociales a finales de la Edad Media. Palencia.

Serrano, L. 1935-1936. El Obispado de Burgos y Castilla primitiva. Siglos V-XIII. Madrid: Instituto Valencia de don Juan. 3 vols.

\section{BiBLIOGRAFÍA}

Agúndez San Miguel, L. 2014. «Carreras eclesiásticas y redes clientelares en la Castilla bajomedieval: la provisión de beneficios menores en el cabildo de la catedral de Burgos (1456-1470)». Anuario de Estudio Medievales 14,2: 665-687.

Arranz Guzmán, A. 2003. "Las visitas pastorales a las parroquias de la Corona de Castilla durante la Baja Edad Media. Un primer inventario de obispos visitadores». La España medieval 26: 295-339.

Ávila Seoane, N. 2008. «El patrimonio señorial de la Catedral de Segovia al sur del Sistema Central». Las catedrales españolas: fuente de cultura, historia y documentación: 9-23.

Ayala Martínez, C. 2014-215. "La política eclesiástica del Alfonso X. El rey y sus obispos». Alcanate: Revista de estudios alfonsíes 9: 41-106.

201 Valdeón Baruque, J. 1970: 327. 
Carbajal Castro, Á. 2012. «Trascender el espacio de poder. Hacia una caracterización de las escalas de acción en la alta edad media entre las cuencas del Cea y del Pisuerga». Hispania, Revista Española de Historia 241: 367-396.

Casado Alonso, H. 1980. La propiedad eclesiástica en la ciudad de Burgos en el siglo XV. El cabildo catedralicio. Valladolid: Universidad de Valladolid.

Casado Alonso, H. 1982. Historia de Hacienda española:(épocas antigua y medieval): 171-191. (Homenaje a Luis García de Valdeavellano). Ministerio de Hacienda.

Casado Alonso, H. 1991. "Producción agraria, precios y coyuntura económica en la diócesis de Burgos y Palencia a fines de la Edad Media». Historia Medieval IX: 67-110.

Cavero Domínguez, G. 2004. "La mitra y el cabildo en la iglesia de León durante el siglo XIII», en Yarza Luaces, J., Herráez Ortega, M. V. Y Boto Varela, G. (coords.), Congreso Internacional "La catedral de León en la Edad Media»: 77-78.

Casado Alonso, H. 2009. «¿Existió la crisis del siglo XIV? Consideraciones a partir de los datos de la contabilidad de la catedral de Burgos», en Del Val Valdivieso, M. I. y Martínez Sopena, P. (dirs.), Castilla y el mundo feudal: homenaje al profesor Julio Valdeón: III: 9-25.

Cofiño Fernández, I.; Mazarrasa Mowinckel, K. 2006. Ermitas, capillas y santuarios de Cantabria. Santander: Colegio oficial de Aparejadores y Arquitectos técnicos de Cantabria.

Díaz Ibáñez, J. 2003. Iglesia, Sociedad y poder en Castilla. El obispado de Cuenca en la Edad Media, Siglos XII-XV. Cuenca.

Díez Herrera, C. 2000. «Los señoríos monásticos en la Cantabria medieval», en Maruri Villanueva, R. (ed.), La iglesia en Cantabria: 137 157. Santander: Obispado de Santander.

Díez Herrera, C. et alii. 2011. La organización medieval de los territorios del valle del Nansa y Peñarrubia (Cantabria). Santander: Fundación Botín.

Díez Herrera, C. 2015. «El obispado de Burgos en la Baja Edad Media. Formas de fortalecer su jurisdicción frente al monasterio de San Salvador de Oña». Anuario de Estudios Medievales 45/2: 753-782.

Estepa Díez, C. 1993. "Propiedad y señorío en Castilla (siglos XIII-XIV)», en Sarasa Sánchez, E. y Serrano Martín, E. (eds.) Señorío y feudalismo en la península ibérica: 373-426. Zaragoza.

Fernández Conde, F. J. 1993. El señorío del cabildo ovetense. Estructuras agrarias de Asturias en el tardo medievo. Oviedo: Servicio de Publicaciones de la Universidad de Oviedo.

Fortún Pérez de Ciriza, L. J. 2013. "Tiempos de convivencia y cooperación entre monjes y obispos en el siglo XI: de los obispos-abades a los canónigos-monjes». García de Cortázar, J. Á. y Teja Casuso, R. (eds.), Monjes y obispos en la España del románico: entre la convivencia y el conflicto: 42-83. Aguilar de Campoo.

García de Cortázar, J. Á. 2012. "Los monasterios de León y Castilla a mediados del siglo XI: un ejemplo de selección de las especies». García de Cortázar. J. Á. y Teja, R. (eds.), Monjes y monasterios hispanos en la Alta Edad Media: 255-268. Aguilar de Campoo.

García Gallo, A. 1951. «El concilio de Coyanza, Contribución al estudio del derecho canónico en la Alta edad media». A.H.D.E.

García Guinea, M. Á. y Pérez González, J. M. 2007. Enciclopedia de Románico en Cantabria. Aguilar de Campoo: Fundación Santa María la Real.

García Lamas, M. A. 2014. "Ubicación y fisonomías de cabildos y audiencias públicas en al Catedral de Mondoñedo (siglos XIII-XV). Estudios mindoniense: Anuario de estudios histórico-teológicos de la diócesis de Mondoñedo-Ferrol 30: 391-436.

González de Riancho Colongues, A. 2010. El linaje de los Ceballos. Orígenes norteños y memoria medieval. Santander: Grupo publicitario Cruzial. S.L.

González Díez, E. 1987. «Formación y desarrollo del dominio señorial de la iglesia palentina.(1035-1351)», en Actas del / Congreso de Historia de Palencia. Tomo II Fuentes Documentales y Edad Media: 207-308. Valladolid: Diputación Provincial de Palencia.

González Echegaray, M. del C. 1974. Toranzo. Datos para la historiografía de un valle montañés. Santander: Institución Cultural de Cantabria.
Guijarro González, S. 2008. "Jerarquía y redes sociales en la Castilla medieval: La provisión de beneficios eclesiásticos en el cabildo de la Catedral de Burgos (1390-1440)». Anuario de Estudios Medievales 38/1: 271-299.

Larrea Conde, J. J. 2007. "Construir iglesias, construir territorio: las dos fases altomedievales de San Román de Tobillas (Álava)», en López Quiroga, J., Martínez Tejera, A. M. y Morín de Pablos, J. (eds.) Monasteria et territoria. Elites, edilicia y territorio en el Mediterráneo medieval (siglos V-XI): 321-336. Madrid: Universidad Autónoma de Madrid.

Lop Otín, M. J. 2003. El cabildo catedralicio de Toledo en el siglo XV: aspectos institucionales y sociológicos. Madrid: Fundación Ramón Areces.

Loring García, M. I. 1987. «Nobleza e iglesias propias en la Cantabria altomedieval». Studia historica. Historia Medieval 5/2: 89-120.

Luis López, C. 2004. "El cabildo de la iglesia Catedral de Ávila a fines de la Edad Media». Espacio, Tiempo y Forma, Serie III. Historia Medieval 17: 353-369.

Martín, J. L. 1978. "Campesinos vasallos de la Iglesia de Zamora». Estudis d'historia agraria 1: 85-97.

Martín Viso, I. 1996. "Monasterios y poder aristocrático en Castilla en el siglo XI». Brocar 20: 91-133.

Martín Viso, I. 2007. «Monasterios y reordenación del espacio local: un estudio comparado del norte de Zamora y la región de Viseu (siglos IX-XI)», en López Quiroga, J., Martínez Tejera, A. M. y Morin de Pablos, J. (eds.) Monasteria et territoria. Elites, edilicia y territorio en el Mediterráneo medieval (siglos V-XI): 259-273. Madrid: Universidad Autónoma de Madrid.

Martínez Díez, G. (1984). "Los obispados de la Castilla condal hasta la consolidación del obispado de Oca en Burgos en el concilio de Husillos (1088)». Burgense 25 (2): 437.

Martínez García, L. 2001. "Los campesinos solariegos en las behetrías castellanas durante la baja edad media», en Estepa Díez, C y Jular Pérez-Alfaro, C. (coords.). Los señoríos de Behetría: 187-226. Madrid: CSIC.

Martínez García, L. 2007. «El señorío abadengo en Castilla. Consideraciones sobre su formación y desarrollo (ss. XI-XIV)». Edad Media. Revista de Historia 8: 243-277.

Martínez Sopena, P. 1991. "Monasterios particulares, nobleza y reforma eclesiástica en León entre los siglos XI y XII», en Estudios de historia medieval. Homenaje a Luis Suárez Fernández: 323-331. Valladolid: Universidad de Valladolid.

Martínez Sopena, P. 2003. «Fundaciones monásticas y nobleza en los reinos de Castilla y León en la época románica», en García de Cortázar, J. A. (coord.), Monasterios románicos y producción artística: 37-61. Aguilar de Campoo: Fundación de Santa María la Real.

Martínez Sopena, P. 2007. "Aristocracia, monacato y reformas en los siglos XI y XII», en El monacato en los reinos de León y Castilla (siglos VII-XIII), X Congreso de Estudios Medievales 2005: 67-100. Ávila: Fundación Sánchez Albornoz.

Mesones Martínez, R. 1965. «Breve reseña del que fue célebre monasterio de los Santos Mártires San Facundo y Primitivo, en el valle de Iguña». Altamira 2-3: 3-27.

Paniagua Pérez y Ramos, F. (coord.) 2004. En torno a la Catedral de León (Estudios). Universidad de León.

Payo Hernanz, R. J. y Parrado del Olmo, J. M. 2014. La Catedral de Ávila nueve siglos de historia y arte. Burgos.

Peña Bocos, E. y Álvarez Llopis, E. 2000. «La génesis de la organización eclesiástica en el territorio regional», en Maruri Villanueva, Ramón (ed.), La iglesia en Cantabria: 109-136. Santander: Obispado de Santander.

Pereda Llarena, F. J. 1986. Aproximación al estudio del señorío eclesiástico y de la capitación decimal de la sede episcopal burgalesa (Siglos XI-XIII). Universidad de Valladolid (Memoria de Licenciatura inédita).

Pérez Bustamante, R. 1979. Sociedad, Economía, Fiscalidad y Gobierno en las Asturias de Santillana (s. XIII-XV). Santander: Estudio.

Pérez, M. 2012. «El control de lo sagrado como instrumento de poder: los monasterios particulares de la aristocracia altomedieval leonesa». Anuario de Estudios Medievales 42/2: 799-822. 
Pérez, M. 2013. «Aristocracia, monasterios particulares y poder episcopal en el Reino de León: los monasterios de los Flaínez». Trabajos y Comunicaciones 39: 165-176.

Pérez Rodríguez, F. J. 2010. "Los cabildos catedralicios gallegos en la Edad Media: siglos XII-XIV». Semata: Ciencias sociais e humanidades 22: 159-176.

Reglero de la Fuente, C. M. 2006. "Los obispos y sus sedes en los reinos hispánicos occidentales. Mediados del siglo XI-mediados del XII: tradición visigoda y reforma romana». La reforma gregoriana y su proyección en la cristiandad Occidental. Siglos XI-XII: 195-288. Pamplona: Gobierno de Navarra.

Rodríguez Llopis, M. y García Díaz, I. 1994. La sociedad feudal. El cabildo de la Catedral de Murcia en la Baja Edad Media. Murcia.

Ruiz de la Riba et alii. 1994. Cos. Aproximación al proceso de construcción de una aldea cantábrica. Santander: Centro de Estudios Rurales de Cantabria, Universidad de Cantabria.
Serrano, L. 1922. D. Mauricio, obispo de Burgos y fundador de su catedral. Madrid.

Solórzano Telechea, J. Á. 2010. «Concubinarios, herejes y usurpadores: justicia eclesiástica, comunicación y 'propaganda' en Las Montañas del obispado de Burgos en el siglo xV». En la España medieval 33: 233-257.

Sánchez Herrero, J. 1983. "Geografía eclesiástica de Castilla y León. Siglos XIII al XV», en Actas del I Congreso de Historia de Castilla y León. Burgos.

Valdeón Baruque, J. 1970. «Datos para la historia social y económica de la Castilla medieval las rentas de la catedral de Burgos en 1352». Anuario de Historia Económica y Social III: 325-338.

Wood, S. 2006. The propietary church in the medieval west. Oxford University Press, Oxford. 